\title{
Radiomics and imaging genomics in precision medicine
}

\author{
Geewon Lee ${ }^{1,2}$, Ho Yun Lee ${ }^{1}$, Eun Sook Ko ${ }^{1}$, Woo Kyoung Jeong ${ }^{1}$ \\ ${ }^{1}$ Department of Radiology and Center for Imaging Science, Samsung Medical Center, Sungkyunkwan University School of \\ Medicine, Seoul, Korea \\ ${ }^{2}$ Department of Radiology and Medical Research Institute, Pusan National University Hospital, Pusan National University School \\ of Medicine, Busan, Korea
}

Received: February 3, 2017

Revised: February 18, 2017

Accepted: February 24, 2017

Corresponding author:

Ho Yun Lee

Department of Radiology and

Center for Imaging Science,

Samsung Medical Center,

Sungkyunkwan University

School of Medicine, 81 Irwon-ro,

Gangnam-gu, Seoul 06351, Korea

Tel: +82-2-3410-2502

E-mail: hoyunlee96@gmail.com

\begin{abstract}
"Radiomics," a field of study in which high-throughput data is extracted and large amounts of advanced quantitative imaging features are analyzed from medical images, and "imaging genomics," the field of study of high-throughput methods of associating imaging features with genomic data, has gathered academic interest. However, a radiomics and imaging genomics approach in the oncology world is still in its very early stages and many problems remain to be solved. In this review, we will look through the steps of radiomics and imaging genomics in oncology, specifically addressing potential applications in each organ and focusing on technical issues.
\end{abstract}

Keywords: Imaging genomics; Neoplasms; Radiomics
This is an Open Access article distributed under the terms of the Creative Commons Attribution Non-Commercial License (http:// creativecommons.org/licenses/ by-nc/4.0/).

\section{INTRODUCTION}

Medical imaging such as computed tomography (CT), positron emission tomography (PET), or magnetic resonance imaging (MRI) is mandatory in the diagnosis, staging, treatment planning, postoperative surveillance, and response evaluation in the routine management of cancer. Although these conventional modalities provide important information on cancer phenotypes, yet a great deal of genetic and prognostic information remains unrevealed.

Recently, there is universal understanding that genomic heterogeneity exists among and even within tumors and that those differences can play an important role in determining the likelihood of a clinical response to treatment with particular agents [1-4]. In other words, the success of precision medicine requires a clear understanding of each patient's tumoral heterogeneity and individual situation.

Here, "radiomics," a field of study in which high-throughput data is extracted and large amounts of advanced quantitative imaging features are analyzed from medical images, and "imaging genomics," the field of study of high-throughput methods of associating imaging features with genomic data, has gathered academic interest. In other words, investigators have suggested that the hidden information embedded in medical images may become utilized through these 
robust approaches. Indeed, several recent studies employing radiomics and imaging genomics have been found to be useful in quantifying overall tumor spatial complexity and identifying the tumor subregions that drive disease transformation, progression, and drug resistance [5-9]. In this review, we will look through all steps of radiomics and imaging genomics in oncology, specifically addressing potential applications in each organ and focusing on technical issues.

\section{Thorax}

\section{Lung}

Two recent investigations support the importance of intratumor subregional partitioning using multiparametric images $[7,10]$. In one study, researchers successfully divided a tumor into necrotic regions and viable regions by incorporating 18F-fluorodeoxyglucose (18F-FDG) PET and diffusion-weighted MRI, which showed good agreement with histology [7]. In the other study, researchers identified clinically relevant, highrisk subregions in lung cancer using intratumor partitioning of $18 \mathrm{~F} \mathrm{FDG-PET} \mathrm{and} \mathrm{CT} \mathrm{images} \mathrm{[10].}$

Overall, many studies have shown that textural features are associated with tumor stage, metastasis, response, survival, and metagenes in lung cancer [11-16]; thereby, providing evidence that textural features show substantial promise as prognostic indicators in thoracic oncology. Tables 1, 2 demonstrate the current literature about radiomics and imaging genomics in the field of clinical oncology [16-111].

In parallel with the 2011 The International Association for the Study of Lung Cancer (IASLC)/The American Thoracic Society (ATS)/The European Respiratory Society (ERS) classification for lung adenocarcinomas, an extensive volume of literature has covered the subset of subsolid nodules, which correlates with the spectrum of lung adenocarcinoma. Of particular importance is the significance of the presence and degree of a pathologically invasive portion, namely the thickening of alveolar septa and increased cellularity $[112,113]$. Although approximately half of pure ground-glass opacity (GGO) nodules have been reported to have a pathologically invasive component, discrimination between the invasive and non-invasive proportions remains challenging in pure GGO lesions because of limited visual perception and subjective analysis of conventional CT scans [114,115]. Several investigators have demonstrated that quantification and feature extraction of GGO lesions (using numerical values) can find small pathologically invasive components, which are reflected at the medical imaging voxel level and otherwise not visually detectable [116-118]. Entropy or a high attenuation value, such as the 75th percentile $\mathrm{CT}$ attenuation value from histograms, has been reported as a significant differentiation factor for invasive adenocarcinomas [118]. Furthermore, the 97.5th percentile $C T$ attenuation value and the slope of CT attenuation values have been suggested as predictors for future $\mathrm{CT}$ attenuation changes and the growth rate of pure GGO lesions [119]. Overall, lung cancer-specific (GGO-related) radiomic features could provide additional information about tumor invasiveness and progression from other indolent or non-invasive lesions and even predict tumor growth (Fig. 1).

\section{Breast}

This part of the review will be focused on radiomics and imaging genomic researches in breast imaging using MRI texture analysis. Radiomic research has been applied to detect microcalcifications [120], differentiate benign from malignant lesions [121-123], and distinguish between breast cancer subtypes [124,125]. James et al. [120] hypothesized the magnetic susceptibility of microcalcifications leads to directional blurring effects which can be detected by statistical image processing. In their results, their method could detect localized blurring with high diagnostic performance. Regarding the differentiation between benign and malignancy, several studies have found that texture features may differ between them. In the breast two-dimensional co-occurrence matrix features of dynamic contrast-enhanced (DCE) MRI images and signal enhancement ratio maps, three-dimensional and four-dimensional features may be feasible in distinguishing between benign and malignant breast lesions [121-123]. Holli et al. [124] have investigated to differentiate invasive lobular carcinoma (ILC) and invasive ductal carcinoma (IDC) by using different texture methods. In this study, co-occurrence matrix features were significantly different between ILC and IDC, allowing differentiation between these two histological subtypes. Further, these features were superior to the other texture methods applied including histogram analysis, run-length matrix, autoregressive model, and wavelet transform [124].

Regarding texture analysis of breast MR images, this technique has been applied to predict treatment response [126]. Parikh et al. [126] evaluated whether changes in MRI texture features can predict pathologic complete response (pCR) to neoadjuvant chemotherapy. In their study conducted in 36 consecutive primary breast cancer patients, an increase in T2-weighted MRI uniformity and a decrease in T2-weighted MRI entropy after neoadjuvant chemotherapy may be helpful in earlier predicting $\mathrm{pCR}$ than tumor size change. 


\section{PRECISION AND FUTURE MIEDICINE \\ Radiomics and imaging genomics}

Table 1. Radiomics studies of clinical oncology published in literature

\begin{tabular}{|c|c|c|c|c|}
\hline Study & $\begin{array}{c}\text { No. of } \\
\text { patients }\end{array}$ & Cancer type & Modality & Country \\
\hline Paul et al. (2016) [24] & 65 & Esophageal cancer & PET & France \\
\hline Huynh et al. (2017) [25] & 112 & Lung cancer & $\mathrm{CT}$ & USA \\
\hline Lu et al. (2016) [26] & 32 & Lung cancer & $\mathrm{CT}$ & USA \\
\hline Lopez et al. (2017) [27] & 17 & Brain cancer & MRI & USA \\
\hline Yu et al. (2016) [28] & 110 & Brain cancer & MRI & China \\
\hline Ginsburg et al. (2016) [29] & 80 & Prostate cancer & MRI & USA \\
\hline Yu et al. (2017) [30] & 92 & Brain cancer & MRI & China \\
\hline Song et al. (2016) [31] & 339 & Lung cancer & $\mathrm{CT}$ & Korea \\
\hline Coroller et al. (2017) [32] & 85 & Lung cancer & $\mathrm{CT}$ & USA \\
\hline Bogowicz et al. (2016) [33] & $\begin{array}{l}11 \\
11\end{array}$ & $\begin{array}{l}\text { Oropharyngeal cancer } \\
\text { Lung cancer }\end{array}$ & $\mathrm{CT}$ & Switzerland \\
\hline Bae et al. (2017) [34] & 80 & Lung cancer & $\mathrm{CT}$ & Korea \\
\hline Prasanna et al. (2016) [35] & $\begin{array}{r}42 \\
65 \\
120\end{array}$ & $\begin{array}{l}\text { Brain cancer } \\
\text { Breast cancer } \\
\text { Lung cancer }\end{array}$ & $\begin{array}{l}\text { MRI } \\
\text { MRI } \\
\text { CT }\end{array}$ & USA \\
\hline Lohmann et al. (2016) [36] & 47 & Brain cancer & $\begin{array}{l}\text { MRI } \\
\text { PET }\end{array}$ & Germany \\
\hline Li et al. (2016) [37] & 91 & Breast cancer & MRI & USA \\
\hline Shiradkar et al. (2016) [38] & 23 & Prostate cancer & MRI & USA \\
\hline Kickingereder et al. (2016) [39] & 172 & Brain cancer & MRI & Germany \\
\hline Grootjans et al. (2016) [40] & 60 & Lung cancer & PET & The Netherlands \\
\hline Nie et al. (2016) [41] & 48 & Rectal Cancer & MRI & USA \\
\hline Prasanna et al. (2016) [42] & 65 & Brain cancer & MRI & USA \\
\hline McGarry et al. (2016) [43] & 81 & Brain cancer & MRI & USA \\
\hline Desseroit et al. (2016) [44] & 74 & Lung cancer & $\begin{array}{l}\text { PET } \\
\mathrm{CT}\end{array}$ & France \\
\hline Li et al. (2016) [21] & 84 & Breast cancer & MRI & USA \\
\hline Yip et al. (2016) [45] & 348 & Lung cancer & PET & USA \\
\hline Hu et al. (2016) [46] & 40 & Rectal Cancer & $\mathrm{CT}$ & China \\
\hline Giesel et al. (2017) [47] & 148 & $\begin{array}{l}\text { Lung cancer } \\
\text { Malignant melanoma } \\
\text { Gastroenteropancreatic neuroendocrine tumours } \\
\text { Prostate cancer }\end{array}$ & $\mathrm{PET} / \mathrm{CT}$ & Germany \\
\hline Aerts et al. (2016) [48] & 47 & Lung cancer & $\mathrm{CT}$ & USA \\
\hline Huynh et al. (2016) [49] & 219 & Breast cancer & Mammography & USA \\
\hline Choi et al. (2016) [50] & 89 & Lung cancer & $\mathrm{CT}$ & Korea \\
\hline Permuth et al. (2016) [51] & 38 & Pancreatic cancer & $\mathrm{CT}$ & USA \\
\hline Hanania et al. (2016) [52] & 53 & Pancreatic cancer & $\mathrm{CT}$ & USA \\
\hline Flechsig et al. (2016) [53] & 122 & Lung cancer & $\mathrm{PET} / \mathrm{CT}$ & Germany \\
\hline Oliver et al. (2016) [54] & 31 & Lung cancer & $\mathrm{PET} / \mathrm{CT}$ & USA \\
\hline
\end{tabular}

(Continued to the next page) 
Table 1. Continued

\begin{tabular}{|c|c|c|c|c|}
\hline Study & $\begin{array}{l}\text { No. of } \\
\text { patients }\end{array}$ & Cancer type & Modality & Country \\
\hline Grossmann et al. (2016) [55] & 141 & Brain cancer & MRI & USA \\
\hline Hawkins et al. (2016) [56] & 196 & Lung cancer & $\mathrm{CT}$ & USA \\
\hline Obeid et al. (2017) [57] & 63 & Breast cancer & MRI & USA \\
\hline Huang et al. (2016) [58] & 282 & Lung cancer & $\mathrm{CT}$ & China \\
\hline Gnep et al. (2017) [59] & 74 & Prostate cancer & MRI & France \\
\hline Huynh et al. (2016) [60] & 113 & Lung cancer & $\mathrm{CT}$ & USA \\
\hline Huang et al. (2016) [61] & 326 & Colorectal cancer & $\mathrm{CT}$ & China \\
\hline Liang et al. (2016) [62] & 494 & Colorectal cancer & $\mathrm{CT}$ & China \\
\hline Coroller et al. (2016) [63] & 127 & Lung cancer & $\mathrm{CT}$ & USA \\
\hline Antunes et al. (2016) [23] & 2 & Renal cancer & PET/MRI & USA \\
\hline Wu et al. (2016) [64] & 350 & Lung cancer & $\mathrm{CT}$ & USA \\
\hline van Velden et al. (2016) [65] & 11 & Lung cancer & $\mathrm{PET} / \mathrm{CT}$ & The Netherlands \\
\hline Mattonen et al. (2016) [66] & 45 & Lung cancer & $\mathrm{CT}$ & Canada \\
\hline Ghosh et al. (2015) [67] & 78 & Renal cancer & $\mathrm{CT}$ & USA \\
\hline Mattonen et al. (2015) [68] & 22 & Lung cancer & $\mathrm{CT}$ & Canada \\
\hline Lee et al. (2015) [69] & 65 & Brain cancer & MRI & USA \\
\hline Parmar et al. (2015) [70] & 101 & Head and neck cancer & $\mathrm{CT}$ & The Netherlands \\
\hline Oliver et al. (2015) [71] & 23 & Lung cancer & $\mathrm{PET} / \mathrm{CT}$ & USA \\
\hline Fave et al. (2015) [72] & 10 & Lung cancer & $\mathrm{CT}$ & USA \\
\hline Wang et al. (2015) [73] & 84 & Breast cancer & MRI & Japan \\
\hline Echegaray et al. (2015) [74] & 29 & Liver cancer & $\mathrm{CT}$ & USA \\
\hline Yoon et al. (2015) [19] & 539 & Lung cancer & $\mathrm{CT}$ & Korea \\
\hline Cameron et al. (2016) [75] & 13 & Prostate cancer & MRI & USA \\
\hline Ypsilantis et al. (2015) [76] & 107 & Esophageal cancer & PET & UK \\
\hline Parmar et al. (2015) [18] & 464 & Lung cancer & $\mathrm{CT}$ & India \\
\hline Parmar et al. (2015) [77] & 878 & $\begin{array}{l}\text { Lung cancer } \\
\text { Head and neck cancer }\end{array}$ & $\mathrm{CT}$ & India \\
\hline Khalvati et al. (2015) [78] & 40,975 & Prostate cancer & MRI & Canada \\
\hline Leijenaar et al. (2015) [79] & 35 & Lung cancer & PET & The Netherlands \\
\hline Vallieres et al. (2015) [80] & 51 & Lung cancer & $\begin{array}{l}\text { PET } \\
\text { MRI }\end{array}$ & Canada \\
\hline Mackin et al. (2015) [81] & 20 & Lung cancer & $\mathrm{CT}$ & USA \\
\hline Coroller et al. (2015) [82] & 98 & Lung cancer & $\mathrm{CT}$ & The Netherlands \\
\hline Cunliffe et al. (2015) [83] & 106 & Esophageal cancer & $\mathrm{CT}$ & USA \\
\hline Parmar et al. (2014) [84] & 20 & Lung cancer & $\mathrm{CT}$ & India \\
\hline Aerts et al. (2014) [17] & 1,019 & $\begin{array}{l}\text { Lung cancer } \\
\text { Head and neck cancer }\end{array}$ & $\mathrm{CT}$ & USA \\
\hline Velazquez et al. (2013) [85] & 20 & Lung cancer & $\mathrm{CT}$ & The Netherlands \\
\hline Leijenaar et al. (2013) [22] & 11 & Lung cancer & $\mathrm{PET} / \mathrm{CT}$ & The Netherlands \\
\hline
\end{tabular}

$\mathrm{PET}$, positron emission tomography; $\mathrm{CT}$, computed tomography; MRI, magnetic resonance imaging. 
PRECISION AND FUTURE MIEDICINE

Radiomics and imaging genomics

Table 2. Imaging genomics studies of clinical oncology published in literature

\begin{tabular}{|c|c|c|c|c|}
\hline Study & No. of patients & Cancer type & Modality & Country \\
\hline Halpenny et al. (2017) [86] & 188 & Lung cancer & CT & USA \\
\hline Demerath et al. (2017) [87] & 26 & Brain cancer & MRI & Germany \\
\hline Wiestler et al. (2016) [88] & 37 & Brain cancer & MRI & Germany \\
\hline Kickingereder et al. (2016) [89] & 152 & Brain cancer & MRI & Germany \\
\hline Heiland et al. (2016) [90] & 21 & Brain cancer & MRI & Germany \\
\hline Hu et al. (2017) [91] & 48 & Brain cancer & MRI & USA \\
\hline Saha et al. (2016) [92] & 50 & Breast cancer & MRI & USA \\
\hline Mehta et al. (2016) [93] & 35 & Breast cancer & MRI & USA \\
\hline Stoyanova et al. (2016) [94] & 17 & Prostate cancer & MRI & UK \\
\hline Zhao et al. (2016) [95] & 32 & Lung cancer & $\mathrm{CT}$ & USA \\
\hline McCann et al. (2016) [96] & 30 & Prostate cancer & MRI & USA \\
\hline Guo et al. (2015) [97] & 91 & Breast cancer & MRI & USA \\
\hline Zhu et al. (2015) [98] & 91 & Breast cancer & MRI & China \\
\hline Kickingereder et al. (2015) [99] & 288 & Brain cancer & MRI & USA \\
\hline Rao et al. (2016) [100] & 92 & Brain cancer & MRI & Germany \\
\hline Gutman et al. (2015) [101] & 76 & Brain cancer & MRI & USA \\
\hline Renard-Penna et al. (2015) [102] & 106 & Prostate cancer & MRI & USA \\
\hline Grimm et al. (2015) [20] & 275 & Breast cancer & MRI & France \\
\hline Shinagare et al. (2015) [103] & $\begin{array}{r}81 \\
19 \\
3\end{array}$ & Renal cancer & $\begin{array}{l}\mathrm{CT} \\
\mathrm{MRI} \\
\mathrm{CT} / \mathrm{MRI}\end{array}$ & USA \\
\hline Wang et al. (2015) [104] & 146 & Brain cancer & MRI & China \\
\hline Halpenny et al. (2014) [105] & 127 & Lung cancer & $\mathrm{CT}$ & USA \\
\hline Aerts et al. (2014) [17] & 1,019 & $\begin{array}{l}\text { Lung cancer } \\
\text { Head and neck cancer }\end{array}$ & $\mathrm{CT}$ & USA \\
\hline Gevaert et al. (2014) [106] & 55 & Brain cancer & MRI & USA \\
\hline Nair et al. (2014) [107] & 355 & Lung cancer & PET & USA \\
\hline Jamshidi et al. (2014) [108] & 23 & Brain cancer & MRI & USA \\
\hline Karlo et al. (2014) [109] & 233 & Renal cancer & $\mathrm{CT}$ & USA \\
\hline De Ruysscher et al. (2013) [110] & 95 & Lung cancer & $\mathrm{CT}$ & Belgium \\
\hline Gevaert et al. (2012) [16] & 26 & Lung cancer & $\begin{array}{l}\mathrm{CT} \\
\mathrm{PET} / \mathrm{CT}\end{array}$ & USA \\
\hline Zinn et al. (2011) [111] & 78 & Brain cancer & MRI & USA \\
\hline
\end{tabular}

$\mathrm{CT}$, computed tomography; MRI, magnetic resonance imaging; $\mathrm{PET}$, positron emission tomography.

Regarding relationship between patients' outcome in patients treated with neoadjuvant chemotherapy and texture features, Pickles et al. [127] showed that higher entropy in DCE-MR images were associated with poorer outcomes. In preoperative setting, Kim et al. [128] evaluated the relationship between MRI texture features and survival outcomes in 203 patients with primary breast cancer. They only used histogram-based uniformity and entropy in T2-weighted imag- es and contrast-enhanced T1 subtraction images. In multivariate analysis, lower $\mathrm{T} 1$ entropy and higher $\mathrm{T} 2$ entropy were significantly associated with worse outcomes. They concluded patients with breast cancers that appeared more heterogeneous on T2-weighted images (higher entropy) and those that appeared less heterogeneous on contrast-enhanced T1weighted subtraction images (lower entropy) showed worse outcome. 


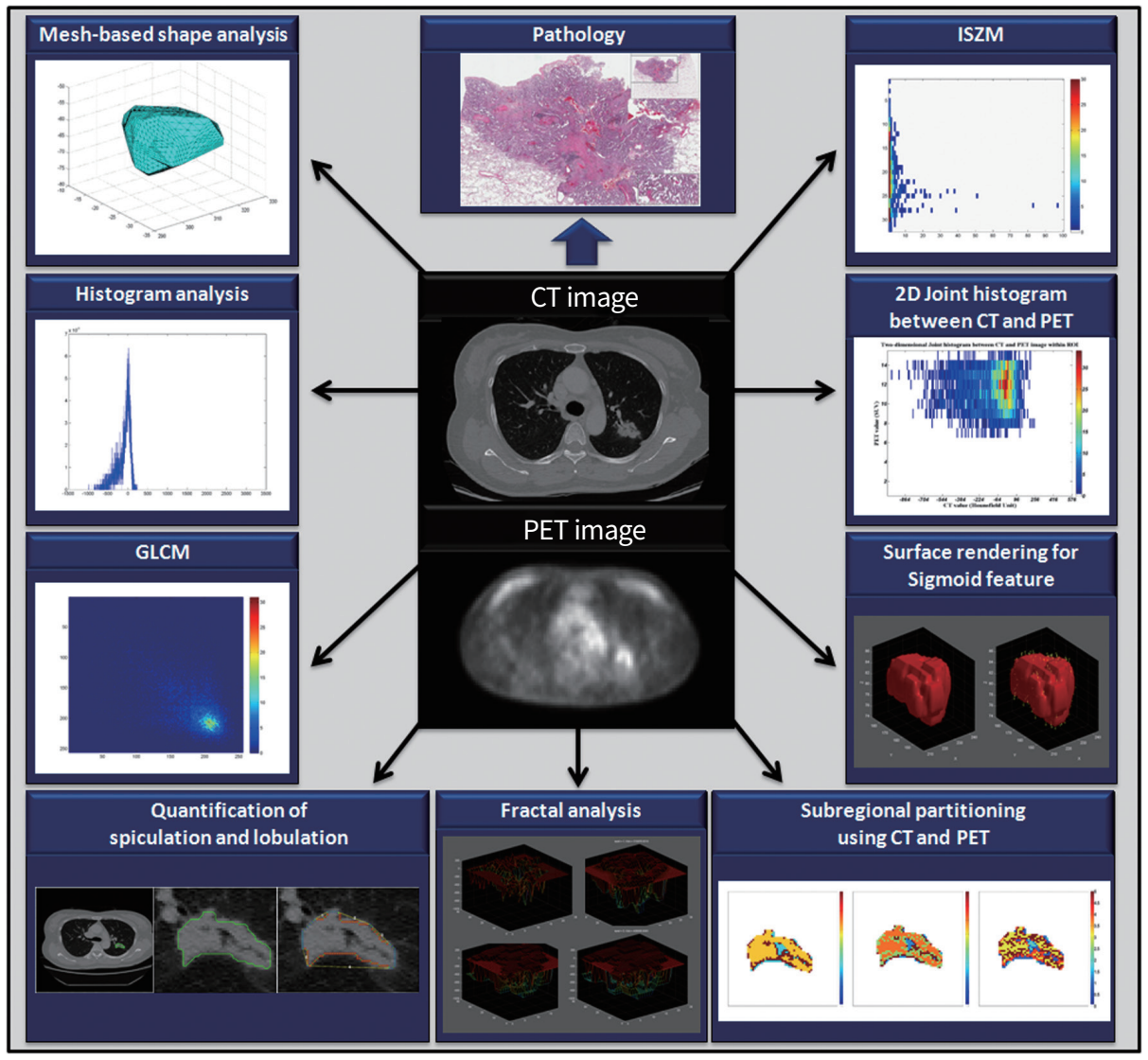

Fig. 1. Various radiomic features, such as mesh-based shape, histogram, gray-level co-occurrence matrix (GLCM), intensity size zone matrix (ISZM), two-dimensional (2D) joint histogram, surface rendering for sigmoid feature, quantification of spiculation and lobulation, fractal analysis, and subregional partitioning, can be extracted from the computed tomography (CT) and positron emission tomography (PET) images of the tumor. The radiomics features are then compared with pathological and clinical data.

\section{Abdomen}

In the abdominal cancers as well, radiomic approaches are very promising to find imaging biomarker for predicting molecular subtyping related to patients' prognosis, to optimize the treatment including selection of chemotherapeutic agent, and to predict the treatment response. Radiology is comprehensive for the treatment of tumor and provides anatomic and morphologic details which are available from CT and MRI. Previously, these details, so called imaging traits, were considered as a single entity, and part of them were generally poorly understood and often ignored. Recently, the recognition of the imaging traits is being highlighted because it may provide consequent information enabling prediction of tumor response to management and prognosis [129]. Especially, given the objective methods to evaluate various imaging methods such as texture analysis which measures objectively the heterogeneity of the lesions by quantifying the patterns of pixel intensities were improved [130], clinical usefulness of radiomics is being expected more and more. Texture analysis, a novel technique, measures objectively the heterogeneity of tumors by quantification of the spatial pattern of pixel intensities on cross-sectional imaging.

Also in the abdomen, some of researchers started to utilize variable imaging modalities as well as conventional $\mathrm{CT}$ or MRI for radiogenomic researches although most of them are pilot studies. Metabolic imaging by PET-CT and hyperpolarized $13 \mathrm{C}$ labeling MRI can be also applied to predict high-grade malignancy and to give an early indication of tumor response $[131,132]$. Recent MRI techniques including diffusion-weighted imaging and hepatobiliary phase imaging after gadoxetic acid administration has been studied the relationship with histologic and clinical phenotypes including microvascular invasion in hepatocellular carcinoma (HCC) and patients' prognosis in intrahepatic cholangiocarcinoma (ICC) [133,134].

Nevertheless, we should overcome some important hurdles against radiomics in the abdominal field: first, it is not easy to obtain volumetric data for abdominal tumors because the tumor boundary is indistinct from the normal tissue or 
adjacent organs compared with the tumor in the lung. For generalized data, acquisition of volumetric data with automatic or semiautomatic manner is necessary [135]. Second, in the case of tumor arising from the hollow viscus, the boundary is more complicated. The shape of tumor on the imaging study might be different from that on the pathologic specimen. Because an intestinal tumor is growing with bowel wall, the lumen of involved bowel may be at the center of the tumor. Therefore, segmentation of adenocarcinoma in the stomach or colon is not easy.

In this part, feasible imaging biomarkers for the abdominal cancers will be addressed and the application of radiomics in the abdominal diseases will be introduced.

\section{Hepatocellular carcinoma}

$\mathrm{HCC}$ is the most common primary cancer of the liver and the second most common cause of cancer-related death. HCC is known as a silent killer which displays minimal symptoms in the early stage of disease and often rarely induce remission despite of the treatment at detection because of the current lack of specific biomarkers. Current staging systems, such as Barcelona Clinic Liver Cancer (BCLC) staging system, do not consider the molecular characteristics of the tumor, even the various etiology of the tumor. Reflecting the varied etiology, HCCs show extreme genetic heterogeneity. And the variability in the prognosis of individuals with HCC suggests that HCC may consist of several distinct biologic phenotypes, which result from activation of different oncogenic pathways during carcinogenesis or from a different cell of origin. In principle, any of the components of a signaling pathway may undergo mutation, although in practice more frequently susceptible genes emerge from genetic screens. Tumor protein P53 (TP53) and $\beta$-catenin are the most frequently mutated genes and are associated with a prognosis $[136,137]$. The other hand, the transcriptional characteristics of HCC can provide insight into the cellular origin of the tumor, and individuals with HCC who shared a gene expression pattern with fetal hepatoblasts had a poor prognosis. Activation of activator protein 1 (AP-1) transcription factors might have key roles in tumor development [138].

\section{Intrahepatic cholangiocarcinoma}

In the ICC, an aggressive primary liver cancer, epidermal growth factor receptor (EGFR), vascular endothelial growth factor (VEGF), and other angiogenic promotors are frequently over-expressed $[139,140]$. According to a study about molecular profiling of cholangiocarcinoma, V-Ki-ras2 Kirsten rat sarcoma viral oncogene homolog (KRAS), phosphatidylinositol 3-kinase catalytic 110-KD alpha (PIK3CA), mesenchymalepithelial transition factor (MET), EGFR, proto-oncogene B-Raf (BRAF), and neuroblastoma rat sarcoma viral oncogene homolog (NRAS) oncogenic mutation were frequently identified in a quarter of ICC patients [141]. These molecular variabilities of ICC cause the expression of microvascular phenotypes related to aggressiveness and tumor size.

\section{Colorectal cancer and hepatic metastasis}

Compared with the liver, texture analyses in the tumor arising from the gastrointestinal tract including colorectal tumors are relatively fewer because the complexity of image data processing including objective (automatic or semi-automatic) tumor segmentation. Some studies endorsed the analysis of the largest cross section of the tumor rather than the whole tumor, but whole tumor analysis is more representative of tumor heterogeneity in colorectal cancer [142]. According to a study about assessment of primary colorectal cancer using whole-tumor texture analysis, entropy, kurtosis, standard deviation, homogeneity, and skewness might be related to 5 -year overall survival of the patients [143]. Unlike from other organs, greater homogeneity at a fine-texture level were associated with a poorer prognosis, leading us to hypothesize that these might be tumors with greater cell packing and more uniform distribution of vascularization and contrast enhancement. In terms of hepatic metastasis, there are several studies focused on hepatic texture in patients with colorectal cancer. In the several studies, increased entropy might be related to the presence of metastasis [144] or poor prognosis after chemotherapy $[145,146]$, but tumor size or volume seemed to be not a predictor of good responders. Therefore, texture analysis could be a good alternative for existing scales for evaluation of tumor response after treatment such as World Health Organization criteria and Response Evaluation Criteria In Solid Tumors (RECIST) criteria.

\section{STEPS OF RADIOMICS}

\section{Image acquisition}

The first step in the radiomics algorithm begins with image acquisition (Fig. 2). However, image acquisition parameters including radiation dose, scanning protocol, reconstruction algorithm, and slice thickness vary widely in routine clinical practice. Therefore, comparison of features extracted from different methods of image acquisition becomes more challenging. Furthermore, several radiomics features were report- 


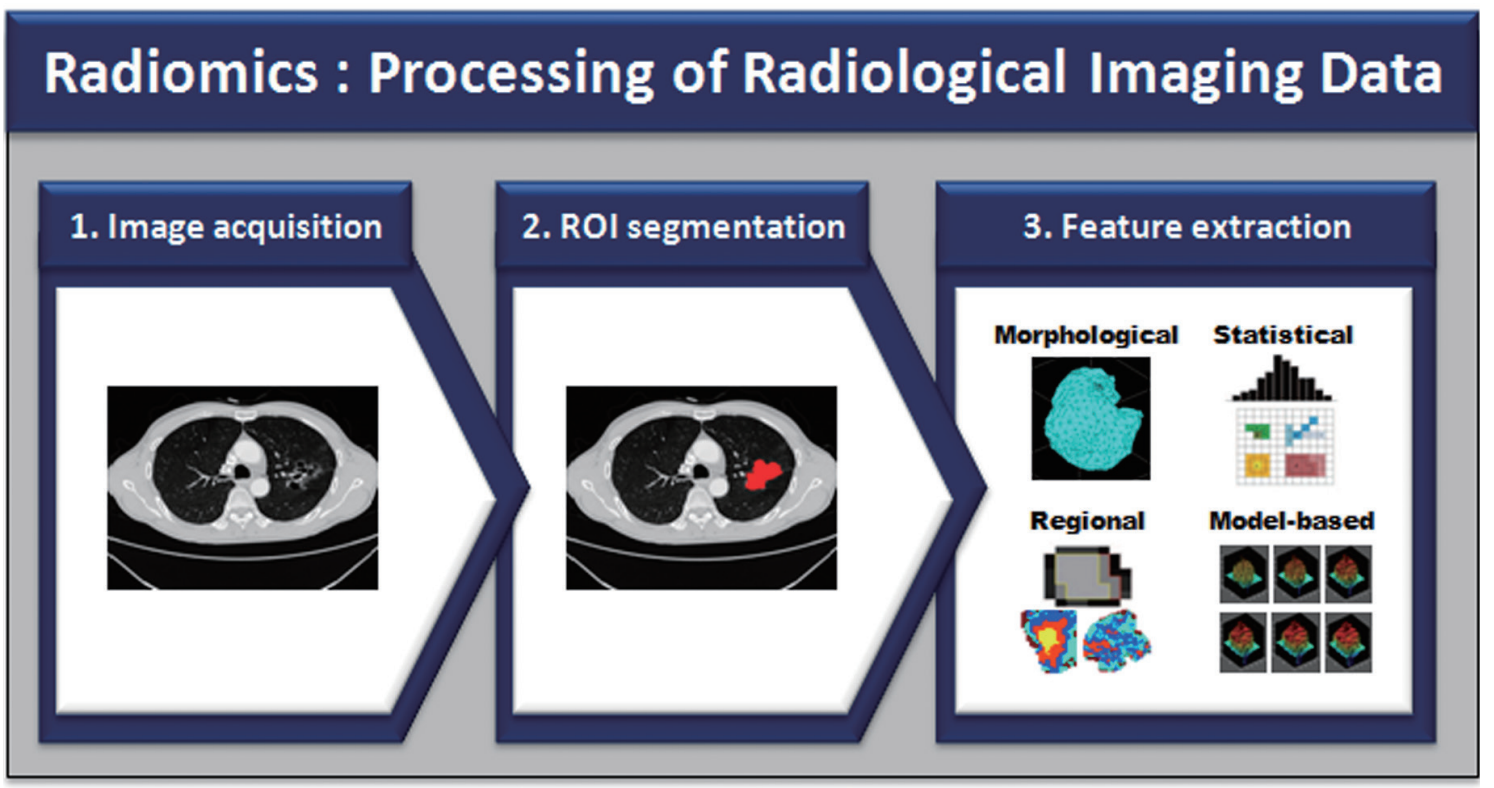

Fig. 2. Radiomics is defined as the processing of radiological imaging data including sequential steps of image acquisition, region of interest (ROI) segmentation, and multiple feature extraction.

ed to be sensitive according to variations in section thickness, pixel size, and reconstruction parameters $[147,148]$. On the other hand, Yan et al. [149] successfully identified several features which remained stable despite different PET image reconstruction settings. Variability issue concerning methods of image acquisition needs to be further investigated.

\section{Segmentation}

Accurate identification of the tumor volume is mandatory for radiomics feature extraction. In most cases, segmentation of the tumor is feasible; however, in certain cases it may be challenging due to indistinct tumor margins $[150,151]$. For example, in the spectrum of lung adenocarcinoma, GGO is always an issue as it may represent the tumor itself or surrounding hemorrhage and inflammation. Among the variable methods of tumor segmentation, automated or semi-automated methods have been reported to be superior to manual methods for segmenting the tumor $[150,152]$.

\section{Feature extraction}

From the identified tumor region, multiple quantitative image features as well as traditional qualitative (semantic) features can be extracted; thus, is the main body of radiomics in oncology. Both quantitative and qualitative (semantic) features have shown some potential for precision medicine in oncology, and these features are continuously being refined and developed with evolving research $[17,117,153]$.
Currently available quantitative radiomic features can be divided into four major classes: (1) morphological, (2) statistical, (3) regional, and (4) model-based. Morphological features are the most basic and provide information about the shape and physical characteristics of a tumor. Statistical features, which are calculated using statistical methods, can be further classified into 1st-order statistical (histogram) features and higher-order statistical (texture) features. These features describe the distribution or spatial arrangement of voxel values within the tumor. Regional features can quantify beyond the immediate neighborhood and represent intratumor clonal heterogeneity. Model-based features are extracted using mathematical approaches, such as the fractal model. Overall, each category yields various quantitative parameters that reflect specific aspects of a tumor.

\section{Feature selection}

With the emergence of precision medicine, developing radiomics features as a biomarker of oncological outcome has become an issue. In this context, a major advantage of radiomics studies is that numerous features which may carry potential as future biomarkers can be extracted from a single tumor region. However, for clinical application, these numerous radiomics features need to be reduced to a number of practical usage, in other words, a selection process for choosing the most prognostic and useful radiomics features is needed. In a large study involving a total of 440 radiomics features, 
according to the different feature selection method and classification method, considerable variability in predictive performance was reported [18].

\section{IMAGING GENOMICS}

Radiomics integrating genomic profiles is called imaging genomics. Imaging genomics researches have become an increasingly important research direction due to its potential to improve disease diagnosis, prognosis, and treatment choice $[10,11]$. As genomic profiling of tumor is generally obtained through invasive procedures such as surgery or biopsy, genomics obtained from noninvasive imaging studies routinely performed in daily practice has the merit. Imaging genomics refers to the relationship between the imaging characteristics of a disease (i.e., the imaging phenotype or radiophenotype), and its gene expression patterns, gene mutations, and other genome-related characteristics $[12,13]$. The primary goals of imaging genomics research are to improve our knowledge of tumor biology and to develop imaging surrogates for genetic testing [13-15].

\section{Lung}

For lung cancers, significant genomic heterogeneity components that affect the likelihood of metastasis and predict response to therapy have been established $[154,155]$. Furthermore, genomic analysis is now essential for appropriate therapeutic planning in this era of precision medicine for advanced lung cancers with distinct tumor subregions. Accordingly, there have been several attempts to explore tumor genomics by applying a radiomic approach. Nevertheless, imaging genomics, the link between genomics and radiomic phenotyping in lung cancer, is still poorly understood.

Preliminary data have associated radiomic features from CT and PET scans in non-small cell lung cancer with each other to predict metagenes with an acceptable accuracy of $65 \%$ to $86 \%$, among which tumor size, edge shape, and sharpness ranked highest for prognostic significance [16]. In one study, the authors performed a detailed analysis of features from 18F-FDG PET in patients with early-stage lung cancer [156]. Multiple features of PET tracer uptake correlated with signatures associated with major oncogenomic alterations in lung cancer $[156,157]$. According to another recent study, the combination of radiomic features and clinical information successfully predicted oncogenic fusion genes in lung cancer [19]. In general, researchers have shown promising results in using radiomics to identify radiographic tumor phenotypes that favored specific genetic expressions $[16,17,19,156,158]$.

\section{Breast}

The published work to date has usually focused on determination of breast cancer molecular subtypes, or correlation with recurrence scores. These early efforts appeared to have great potential and have established a strong basework for future larger-scale research endeavors which will hopefully validate the implementation of breast MRI imaging genomics into clinical practice.

The most popular topic for breast MRI imaging genomics is breast cancer molecular subtypes [20]. Gene expression profiling has made stratification of breast cancers possible into four major molecular subtypes (luminal A, luminal B, human epidermal growth factor receptor-2 [HER2], and basal like) $[159,160]$. These different molecular subtypes have been regarded as important because each subtype are supposed to show different patterns of disease expression, response to therapy, and prognosis [161-163]. The most common molecular subtype, luminal A typically concurs with the best prognosis [159], while luminal B subtype shows good response to radiation therapy and has intermediate survival [164], in contrast to HER2 and basal subtypes, which display good response to chemotherapy but have the worst overall survival [161]. Based on prior results, oncologists take advantage of these molecular subtypes when making decisions about systemic treatment in daily practice [165].

Usual way to determine molecular subtype is based on immunohistochemistry (IHC) patterns of estrogen receptor (ER), progesterone receptor (PR), HER2, and Ki-67 expression [165]. These IHC findings are replaced expensive genetic tests and used as surrogate marker [165-167]. Agreement between IHC surrogate markers and genetic testing ranges from $41 \%$ to $100 \%$ and IHC surrogate markers have been shown to be less robust about predicting outcomes [168]. Therefore, more accurate means of classifying molecular subtypes are needed and imaging genomics is regarded as strong candidate.

There are two published articles that have attempted to build models based on imaging features to predict molecular subtype $[20,125]$. Waugh et al. [125] in a study of 148 cancers and 73 test sets, used texture analysis derived from $220 \mathrm{im}$ aging features to evaluate surrogate molecular subtypes. Unfortunately, the authors were only able to display a classification accuracy of $57.2 \%$ with an area under the receiver operating characteristic (AUC) curve of 0.754. Nevertheless, the authors identified that entropy features, which refer to internal pixel distribution patterns that are representative of growth 
patterns, were the best features to discriminate among breast cancer subtypes. They conclude that their study may have been underpowered to assess the performance of a model due to the small number of features. Grimm et al. [20] used 56 imaging features, including morphologic, texture, and dynamic features, to evaluate surrogate molecular subtypes in 275 breast cancers. At multivariate analysis, their results showed a strong association between the collective imaging features and both luminal $A(P=0.0007)$ and luminal $B(P=0.0063)$ breast cancers.

The first commercially available genomic biomarker was 21-gene recurrence score (Oncotype DX, Genomic Health, Redwood City, CA, USA) which guided treatment decisions [169, 170]. Oncotype DX was developed to quantify the likelihood of disease recurrence in patients with early stage invasive breast cancer who were ER-positive and lymph node- negative. Results consists of three categories: low-, intermediate-, or high-risk. Patients at low-risk are thought to derive minimal benefit from the addition of chemotherapy to standard hormonal therapy. The 21-gene recurrence score is included within the treatment guidelines from the National Cancer Care Network and the American Society of Clinical Oncology $[171,172]$. Several additional commercially available genomic biomarkers have also been designed to predict recurrence of therapeutic response, such as MammaPrint (Agendia, Amsterdam, the Netherlands), Mammostrat (Clarient Diagnostic Services, Aliso Viejo, CA, USA), PAM50 (Prosigna, Seattle, WA, USA), but these tests are newer and not yet widely used clinically. Recently, investigators have explored associations between 21-gene recurrence scores and breast MRI, but still there are no published studies about the newer genomic biomarkers which may provide an opportunity for future investigations [173-175]. In a study of 98 patients who underwent preoperative breast MRI and Oncotype DX recurrence score testing, Sutton et al. [175] reported similar results while investigating 44 morphologic and texture imaging features. At multivariate analysis, kurtosis on the first $(P=0.0056)$ and third $(P=0.0005)$ postcontrast sequences was significantly correlated with recurrence scores. Recently, Li et al. [21] investigated relationship between computer-extracted MRI phenotypes
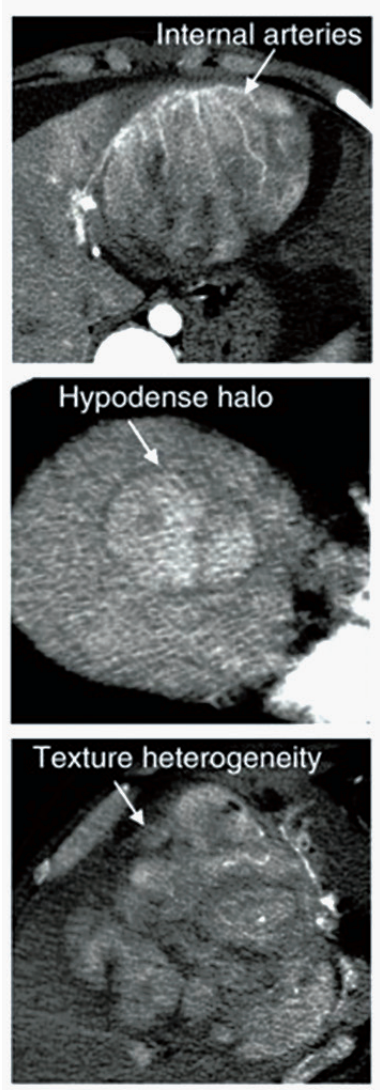
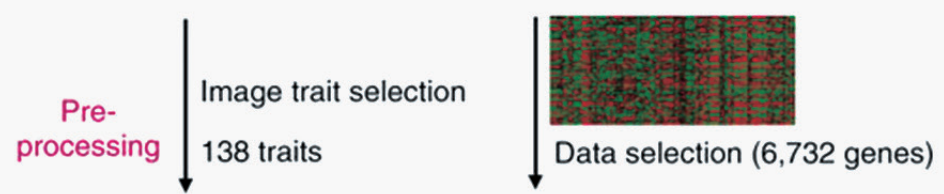

Image traits

Expression data

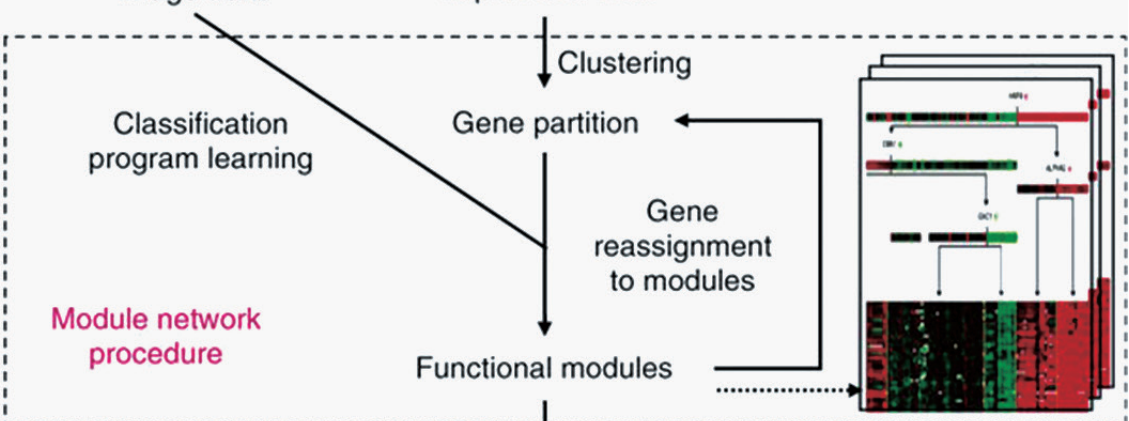

A

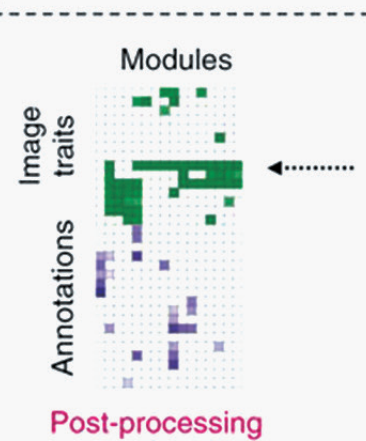

Functional modules

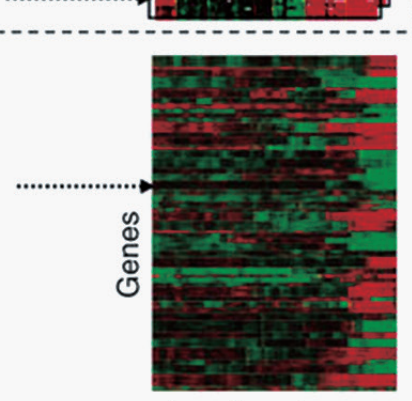

Imaging classes

Fig. 3. Imaging traits of hepatocellular carcinoma (HCC) and gene expression. (A) Three imaging traits in HCC: internal arteries, hypodense halo, and texture heterogeneity. (B) Strategy to make an association map between imaging traits and gene expression. Reprinted from Segal et al. [176], with permission from Nature Publishing Group. 
with multigene assays of MammaPrint, Oncotype DX, and PAM50 to evaluate the role of radiomics in assessing the risk of breast cancer recurrence on 84 patients. On multivariate analysis, significant associations between radiomics signatures and multigene assay recurrence scores were reported. Use of radiomics for distinguishing poor and good prognosis demonstrated AUC values of $0.88,0.76$, and 0.68 for MammaPrint, Oncotype Dx, and PAM50 risk of relapse based on subtype, respectively.

\section{Abdomen}

Imaging genomics about HCC is a very early stage, but initial result by Segal and his colleagues [176] was promising. On the basis of several different imaging traits, tumors with internal arteries and an absence of hypodense halos were related to increased specific gene expression resulting in increased risk for microvascular invasion (Fig. 3). The presence of internal arteries was also an independent factor for a poor prognosis [176]. Researchers of the previous paper maintained the imaging genomic study about prediction of microvascular invasion of HCC, and they introduced radiogenomic venous invasion (RVI) which is a contrast-enhanced CT biomarker of microvascular invasion derived from a 91-gene HCC gene expression. They revealed that the diagnostic accuracy of RVI

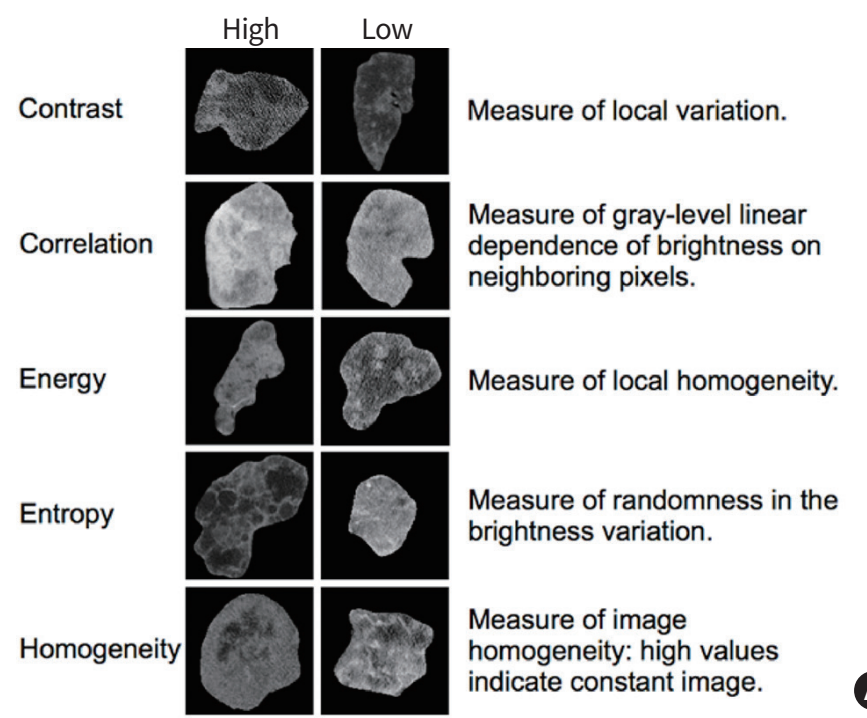

A

a. Protein expression

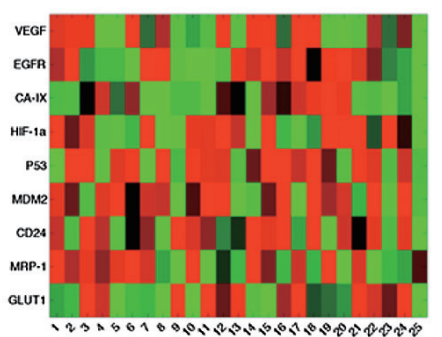

b. Texture analysis

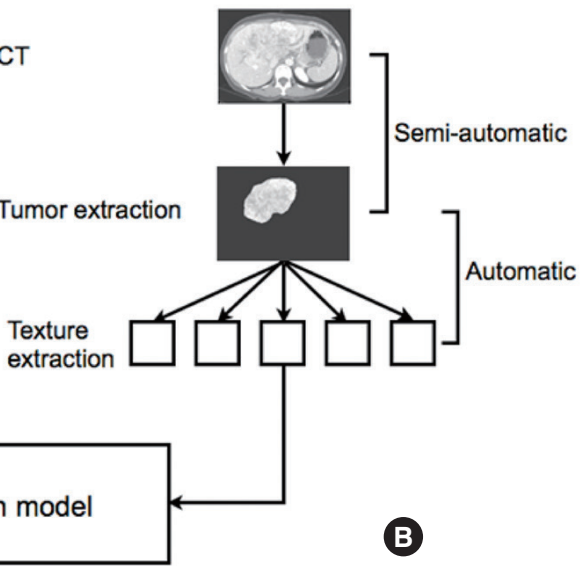

Fig. 4. Representative texture features of intrahepatic cholangiocarcinoma. (A) Quantitative image phenotypes derived from texture analysis. These features are automatically computed based on the region of interest extracted from computed tomography (CT). (B) Schematic process for making the prediction model of intrahepatic cholangiocarcinoma. Reprinted from Sadot et al. [180]. VEGF, vascular endothelial growth factor; EGFR, epidermal growth factor receptor; CA-IX, carbonic anhydrase IX; HIF-1 $\alpha$, hypoxia-inducible factor 1 $\alpha$; P53, protein p53; MDM2, mouse double minute 2 homolog; CD24, cluster of differentiation 24; MRP-1, multidrug resistance-associated protein 1; GLUT1, glucose transporter 1. 
was $89 \%$, and positive RVI score was associated with lower overall survival than negative RVI score in the study cohorts [177]. Kitao and his colleague [178] concentrated to HCC with $\beta$-catenin mutation. The $\beta$-catenin mutation is known that it is associated with the promotion of carcinogenesis and acceleration of bile production with a relatively favorable prognosis. They evaluated gadoxetic acid-enhanced MRI, and explored some parametric variables including contrast-to-noise ratio, apparent diffusion coefficient (ADC) of diffusion-weighted imaging, and enhancement ratio of postcontrast imaging. They concluded HCC with $\beta$-catenin mutation predicted by characteristic imaging parameters including high enhancement ratio at gadoxetic acid-enhanced MRI and high ADC at diffusion-weighted imaging had significant positive correlations among phenotypes such as expression of $\beta$-catenin, glutamine synthetase, and organic anion transporting polupeptide 1B3 (OATP1B3) [178]. In terms of prognostic consequences, imaging genomics may be useful to decide therapeutic options. The gene expression related to doxorubicin resistance in $\mathrm{HCC}$ cells was investigated and some associated imaging traits were examined. Doxorubicin is a chemotherapeutic drug usually used with transcatheter arterial chemoembolization. Among these imaging traits, a poorly defined tumor margin was considered a significantly related factor of the doxorubicin resistance [179].

Although the imaging genomic study about ICC is not common, an interesting study using a texture analysis of $\mathrm{CT}$ data in patients with ICC was recently published (Fig. 4) [180]. They focused on the relationship between the heterogeneity in tumor enhancement pattern of ICC and a molecular profile based on hypoxia markers, such as VEGF, EGFR, cluster of differentiation 24 (CD24), multidrug resistance-associated protein 1 (MRP-1), hypoxia-inducible factor $1 a$ (HIF-1a), glucose transporter 1 (GLUT1), carbonic anhydrase IX (CA-IX), mouse double minute 2 homolog (MDM2), and P53. On the result, the combination of entropy, correlation, and homogeneity was significantly related to EGFR and CD24 expression, and it might be meaningful imaging textures quantifying visible variations in enhancement. The hypoxic microenvironment and abnormal vasculature derived by these molecules leads to tumor-related angiogenesis which affects local tumor growth and metastasis, which supports that several anti-angiogenic agents such as bevacizumab (anti-VEGF antibody) and cetuximab (anti-EGFR antibody) are used for the patients with advanced ICC $[181,182]$. Furthermore, CD24 is a cell adhesion molecule associated with chemoresistance capability and poor survival in ICC. Recently, CD24 is considered an emerging target for directed molecular therapy, as decreased invasiveness was

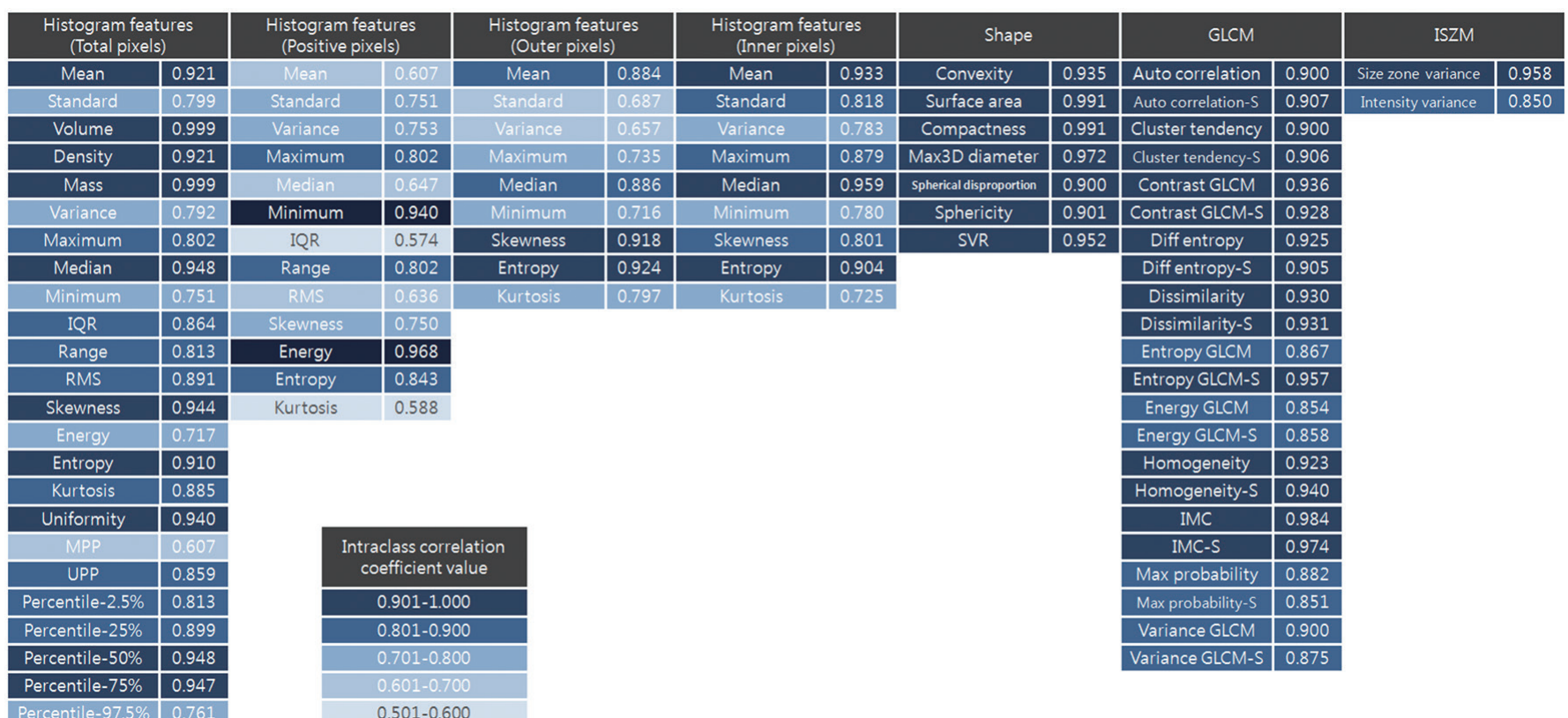

Fig. 5. Intraclass correlation coefficient values are depicted for each radiomics feature belonging to seven categories. Darker colors have greater reproducibility. Note the overall high correlation of radiomics features. IQR, interquartile range; RMS, root mean square; MPP, mean value of positive pixels; UPP, uniformity of distribution of positive pixels; Max3D, maximum three-dimensional diameter; SVR, surface to volume ratio; GLCM, gray-level co-occurrence matrix; GLCM-S, gray level co-occurrence matrix subsampled; IMC, informational measure of correlation; IMC-S, informational measure of correlation subsampled; ISZM, intensity size zone matrix. 
observed with CD24 inhibition [183].

\section{PARTICULAR CONSIDERATIONS REGARDING RADIOMIC APPROACH}

\section{Reproducibility of features and study results}

Although a large number of radiomics features have shown potential in tumor response and prognosis, reproducibility of radiomics features and study results remain challenging. Unfortunately, several early investigators have reported that many features were often unstable [184-186]. In a study of 219 radiomics features, only 66 features reported intraclass correlation coefficient value of more than 0.90 [184,185]. Fig. 5 depicts the ICC distributions among radiomics features according to color. Hence, validation across different institutions may serve as the solution for reproducibility of features and study results.

\section{Issues of imaging modality}

Special consideration is required to apply radiomics due to MR specific characteristics, intensity inhomogeneity which can significantly affect radiomic feature extraction $[23,187]$. Thus, before registration of MR images, the necessity of bias field correction by convolving the images with a Gaussian low-pass filter, resulting in uniform intensities across the volume should be inquired [188]. Furthermore, the stability of MRI-based radiomics features has not been investigated, and thus would be a valuable future study.

\section{CONCLUSION}

A radiomics and imaging genomics approach in the oncology world is still in its very early stages and many problems remain to be solved. However, in the close future, we believe that radiomics and imaging genomics will play a significant role of performing image genotyping and phenotyping to enhance the role of medical imaging in precision medicine.

\section{CONFLICTS OF INTEREST}

No potential conflict of interest relevant to this article was reported.

\section{ACKNOWLEDGMENTS}

We are thankful to Professor Hyunjin Park from School of Electronic and Electrical Engineering and Center for Neuro- science Imaging Research, Sungkyunkwan University, Suwon, Korea, Seung-Hak Lee and Jonghoon Kim from Department of Electronic Electrical and Computer Engineering and Center for Neuroscience Imaging Research, Sungkyunkwan University, Suwon, Korea, who devoted their time and knowledge in technical support to provide graphic figures for this study.

\section{REFERENCES}

1. Burrell RA, McGranahan N, Bartek J, Swanton C. The causes and consequences of genetic heterogeneity in cancer evolution. Nature 2013;501:338-45.

2. Greaves M, Maley CC. Clonal evolution in cancer. Nature 2012;481:306-13.

3. Jamal-Hanjani M, Quezada SA, Larkin J, Swanton C. Translational implications of tumor heterogeneity. Clin Cancer Res 2015;21:1258-66.

4. Swanton C. Intratumor heterogeneity: evolution through space and time. Cancer Res 2012;72:4875-82.

5. Chen L, Choyke PL, Chan TH, Chi CY, Wang G, Wang Y. Tissue-specific compartmental analysis for dynamic contrast-enhanced MR imaging of complex tumors. IEEE Trans Med Imaging 2011;30:2044-58.

6. Chong Y, Kim JH, Lee HY, Ahn YC, Lee KS, Ahn MJ, et al. Quantitative CT variables enabling response prediction in neoadjuvant therapy with EGFR-TKIs: are they different from those in neoadjuvant concurrent chemoradiotherapy? PLoS One 2014;9:e88598.

7. Divine MR, Katiyar P, Kohlhofer U, Quintanilla-Martinez L, Pichler BJ, Disselhorst JA. A population-based Gaussian mixture model incorporating 18F-FDG PET and diffusionweighted MRI quantifies tumor tissue classes. J Nucl Med 2016;57:473-9.

8. Messiou C, Orton M, Ang JE, Collins DJ, Morgan VA, Mears $D$, et al. Advanced solid tumors treated with cediranib: comparison of dynamic contrast-enhanced MR imaging and CT as markers of vascular activity. Radiology 2012; 265:426-36.

9. Son JY, Lee HY, Kim JH, Han J, Jeong JY, Lee KS, et al. Quantitative CT analysis of pulmonary ground-glass opacity nodules for distinguishing invasive adenocarcinoma from non-invasive or minimally invasive adenocarcinoma: the added value of using iodine mapping. Eur Radiol 2016;26:43-54.

10. Wu J, Gensheimer MF, Dong X, Rubin DL, Napel S, Diehn $M$, et al. Robust intratumor partitioning to identify high- 
risk subregions in lung cancer: a pilot study. Int J Radiat Oncol Biol Phys 2016;95:1504-12.

11. Al-Kadi OS, Watson D. Texture analysis of aggressive and nonaggressive lung tumor CE CT images. IEEE Trans Biomed Eng 2008;55:1822-30.

12. Cook GJ, Yip C, Siddique M, Goh V, Chicklore S, Roy A, et al. Are pretreatment 18F-FDG PET tumor textural features in non-small cell lung cancer associated with response and survival after chemoradiotherapy? J Nucl Med 2013; 54:19-26.

13. Fried DV, Tucker SL, Zhou S, Liao Z, Mawlawi O, Ibbott G, et al. Prognostic value and reproducibility of pretreatment CT texture features in stage III non-small cell lung cancer. Int J Radiat Oncol Biol Phys 2014;90:834-42.

14. Ganeshan B, Abaleke S, Young RC, Chatwin CR, Miles KA. Texture analysis of non-small cell lung cancer on unenhanced computed tomography: initial evidence for a relationship with tumour glucose metabolism and stage. Cancer Imaging 2010;10:137-43.

15. Ganeshan B, Panayiotou E, Burnand K, Dizdarevic S, Miles $\mathrm{K}$. Tumour heterogeneity in non-small cell lung carcinoma assessed by $\mathrm{CT}$ texture analysis: a potential marker of survival. Eur Radiol 2012;22:796-802.

16. Gevaert O, Xu J, Hoang CD, Leung AN, Xu Y, Quon A, et al. Non-small cell lung cancer: identifying prognostic imaging biomarkers by leveraging public gene expression microarray data: methods and preliminary results. Radiology 2012;264:387-96.

17. Aerts HJ, Velazquez ER, Leijenaar RT, Parmar C, Grossmann P, Carvalho S, et al. Decoding tumour phenotype by noninvasive imaging using a quantitative radiomics approach. Nat Commun 2014;5:4006.

18. Parmar C, Grossmann P, Bussink J, Lambin P, Aerts HJ. Machine learning methods for quantitative radiomic biomarkers. Sci Rep 2015;5:13087.

19. Yoon HJ, Sohn I, Cho JH, Lee HY, Kim JH, Choi YL, et al. Decoding tumor phenotypes for ALK, ROS1, and RET fusions in lung adenocarcinoma using a radiomics approach. Medicine (Baltimore) 2015;94:e1753.

20. Grimm LJ, Zhang J, Mazurowski MA. Computational approach to radiogenomics of breast cancer: luminal $A$ and luminal $B$ molecular subtypes are associated with imaging features on routine breast MRI extracted using computer vision algorithms. J Magn Reson Imaging 2015; 42:902-7.

21. Li H, Zhu Y, Burnside ES, Drukker K, Hoadley KA, Fan C, et al. MR imaging radiomics signatures for predicting the risk of breast cancer recurrence as given by research versions of MammaPrint, Oncotype DX, and PAM50 gene assays. Radiology 2016;281:382-91.

22. Leijenaar RT, Carvalho S, Velazquez ER, van Elmpt WJ, Parmar C, Hoekstra OS, et al. Stability of FDG-PET radiomics features: an integrated analysis of test-retest and inter-observer variability. Acta Oncol 2013;52:1391-7.

23. Antunes J, Viswanath S, Rusu M, Valls L, Hoimes C, Avril $\mathrm{N}$, et al. Radiomics analysis on FLT-PET/MRI for characterization of early treatment response in renal cell carcinoma: a proof-of-concept study. Transl Oncol 2016;9: 155-62.

24. Paul D, Su R, Romain M, Sebastien V, Pierre V, Isabelle G. Feature selection for outcome prediction in oesophageal cancer using genetic algorithm and random forest classifier. Comput Med Imaging Graph. 2016 Dec 28 [Epub]. http://doi.org/10.1016/j.compmedimag.2016.12.002.

25. Huynh E, Coroller TP, Narayan V, Agrawal V, Romano J, Franco I, et al. Associations of radiomic data extracted from static and respiratory-gated CT scans with disease recurrence in lung cancer patients treated with SBRT. PLoS One 2017;12:e0169172.

26. Lu L, Ehmke RC, Schwartz LH, Zhao B. Assessing agreement between radiomic features computed for multiple CT imaging settings. PLoS One 2016;11:e0166550.

27. Lopez CJ, Nagornaya N, Parra NA, Kwon D, Ishkanian F, Markoe AM, et al. Association of radiomics and metabolic tumor volumes in radiation treatment of glioblastoma multiforme. Int J Radiat Oncol Biol Phys 2017;97: 586-95.

28. Yu J, Shi Z, Lian Y, Li Z, Liu T, Gao Y, et al. Noninvasive IDH1 mutation estimation based on a quantitative radiomics approach for grade II glioma. Eur Radiol. 2016 Dec 21 [Epub]. http://doi.org/10.1007/s00330-016-4653-3.

29. Ginsburg SB, Algohary A, Pahwa S, Gulani V, Ponsky L, Aronen $\mathrm{HJ}$, et al. Radiomic features for prostate cancer detection on MRI differ between the transition and peripheral zones: preliminary findings from a multi-institutional study. J Magn Reson Imaging. 2016 Dec 19 [Epub]. http://doi.org/10.1002/jmri.25562.

30. Yu J, Shi Z, Ji C, Lian Y, Wang Y, Chen L, et al. Anatomical location differences between mutated and wild-type isocitrate dehydrogenase 1 in low-grade gliomas. Int J Neurosci. 2017 Jan 6 [Epub]. http://doi.org/10.1080/002 07454.2016.1270278.

31. Song SH, Park H, Lee G, Lee HY, Sohn I, Kim HS, et al. Imaging phenotyping using radiomics to predict micropap- 


\section{PRECISION AND FUTURE MIEDICINE}

Radiomics and imaging genomics

illary pattern within lung adenocarcinoma. J Thorac Oncol 2017;12:624-32.

32. Coroller TP, Agrawal V, Huynh E, Narayan V, Lee SW, Mak $\mathrm{RH}$, et al. Radiomic-based pathological response prediction from primary tumors and lymph nodes in NSCLC. J Thorac Oncol 2017;12:467-76.

33. Bogowicz M, Riesterer O, Bundschuh RA, Veit-Haibach P, Hullner M, Studer G, et al. Stability of radiomic features in CT perfusion maps. Phys Med Biol 2016;61:8736-49.

34. Bae JM, Jeong JY, Lee HY, Sohn I, Kim HS, Son JY, et al. Pathologic stratification of operable lung adenocarcinoma using radiomics features extracted from dual energy CT images. Oncotarget 2017;8:523-35.

35. Prasanna P, Tiwari P, Madabhushi A. Co-occurrence of local anisotropic gradient orientations (CoLlAGe): a new radiomics descriptor. Sci Rep 2016;6:37241.

36. Lohmann P, Stoffels G, Ceccon G, Rapp M, Sabel M, Filss $\mathrm{CP}$, et al. Radiation injury vs. recurrent brain metastasis: combining textural feature radiomics analysis and standard parameters may increase 18F-FET PET accuracy without dynamic scans. Eur Radiol. 2016 Nov 16 [Epub]. http://doi.org/10.1007/s00330-016-4638-2.

37. Li H, Zhu Y, Burnside ES, Huang E, Drukker K, Hoadley $\mathrm{KA}$, et al. Quantitative MRI radiomics in the prediction of molecular classifications of breast cancer subtypes in the TCGA/TCIA data set. NPJ Breast Cancer. 2016 May 11 [Epub]. http://doi.org/10.1038/npjbcancer.2016.12.

38. Shiradkar R, Podder TK, Algohary A, Viswanath S, Ellis RJ, Madabhushi A. Radiomics based targeted radiotherapy planning (Rad-TRaP): a computational framework for prostate cancer treatment planning with MRI. Radiat Oncol 2016;11:148.

39. Kickingereder P, Gotz M, Muschelli J, Wick A, Neuberger $\mathrm{U}$, Shinohara RT, et al. Large-scale radiomic profiling of recurrent glioblastoma identifies an imaging predictor for stratifying anti-angiogenic treatment response. Clin Cancer Res 2016;22:5765-71.

40. Grootjans W, Tixier F, van der Vos CS, Vriens D, Le Rest CC, Bussink J, et al. The impact of optimal respiratory gating and image noise on evaluation of intratumor heterogeneity on 18F-FDG PET imaging of lung cancer. J Nucl Med 2016;57:1692-8.

41. Nie K, Shi L, Chen Q, Hu X, Jabbour SK, Yue N, et al. Rectal cancer: assessment of neoadjuvant chemoradiation outcome based on radiomics of multiparametric MRI. Clin Cancer Res 2016;22:5256-64.

42. Prasanna P, Patel J, Partovi S, Madabhushi A, Tiwari P.
Radiomic features from the peritumoral brain parenchyma on treatment-naive multi-parametric MR imaging predict long versus short-term survival in glioblastoma multiforme: preliminary findings. Eur Radiol. 2016 Oct 24 [Epub]. http://doi.org/10.1007/s00330-016-4637-3.

43. McGarry SD, Hurrell SL, Kaczmarowski AL, Cochran EJ, Connelly J, Rand SD, et al. Magnetic resonance imaging-based radiomic profiles predict patient prognosis in newly diagnosed glioblastoma before therapy. Tomography 2016;2:223-8.

44. Desseroit MC, Tixier F, Weber WA, Siegel BA, Cheze Le Rest C, Visvikis D, et al. Reliability of PET/CT shape and heterogeneity features in functional and morphological components of non-small cell lung cancer tumors: a repeatability analysis in a prospective multi-center cohort. J Nucl Med 2017;58:406-11.

45. Yip SS, Kim J, Coroller T, Parmar C, Rios Velazquez E, Huynh E, et al. Associations between somatic mutations and metabolic imaging phenotypes in non-small cell lung cancer. J Nucl Med. 2016 Sep 29 [Epub]. http://doi. org/10.2967/jnumed.116.181826.

46. Hu P, Wang J, Zhong H, Zhou Z, Shen L, Hu W, et al. Reproducibility with repeat $\mathrm{CT}$ in radiomics study for rectal cancer. Oncotarget 2016;7:71440-6.

47. Giesel FL, Schneider F, Kratochwil C, Rath D, Moltz J, Holland-Letz T, et al. Correlation between SUVmax and CT radiomic analysis using lymph node density in PET/ CT-based lymph node staging. J Nucl Med 2017;58:282-7.

48. Aerts HJ, Grossmann P, Tan Y, Oxnard GG, Rizvi N, Schwartz $\mathrm{LH}$, et al. Defining a radiomic response phenotype: a pilot study using targeted therapy in NSCLC. Sci Rep 2016;6:33860.

49. Huynh BQ, Li H, Giger ML. Digital mammographic tumor classification using transfer learning from deep convolutional neural networks. J Med Imaging (Bellingham) 2016;3:034501.

50. Choi ER, Lee HY, Jeong JY, Choi YL, Kim J, Bae J, et al. Quantitative image variables reflect the intratumoral pathologic heterogeneity of lung adenocarcinoma. Oncotarget 2016;7:67302-13.

51. Permuth JB, Choi J, Balarunathan Y, Kim J, Chen DT, $C$ hen $\mathrm{L}$, et al. Combining radiomic features with a miRNA classifier may improve prediction of malignant pathology for pancreatic intraductal papillary mucinous neoplasms. Oncotarget 2016;7:85785-97.

52. Hanania AN, Bantis LE, Feng Z, Wang H, Tamm EP, Katz $\mathrm{MH}$, et al. Quantitative imaging to evaluate malignant 
potential of IPMNs. Oncotarget 2016;7:85776-84.

53. Flechsig P, Frank P, Kratochwil C, Antoch G, Rath D, Moltz $J$, et al. Radiomic analysis using density threshold for FDG-PET/CT-based N-staging in lung cancer patients. Mol Imaging Biol 2017;19:315-22.

54. Oliver JA, Budzevich M, Hunt D, Moros EG, Latifi K, Dilling $T J$, et al. Sensitivity of image features to noise in conventional and respiratory-gated PET/CT images of lung cancer: uncorrelated noise effects. Technol Cancer Res Treat. 2016 Aug 8 [Epub]. http://doi.org/10.1177/15330 34616661852.

55. Grossmann P, Gutman DA, Dunn WD Jr, Holder CA, Aerts HJ. Imaging-genomics reveals driving pathways of MRI derived volumetric tumor phenotype features in glioblastoma. BMC Cancer 2016;16:611.

56. Hawkins S, Wang H, Liu Y, Garcia A, Stringfield O, Krewer $\mathrm{H}$, et al. Predicting malignant nodules from screening CT scans. J Thorac Oncol 2016;11:2120-8.

57. Obeid JP, Stoyanova R, Kwon D, Patel M, Padgett K, Slingerland J, et al. Multiparametric evaluation of preoperative MRI in early stage breast cancer: prognostic impact of peri-tumoral fat. Clin Transl Oncol 2017;19:211-8.

58. Huang Y, Liu Z, He L, Chen X, Pan D, Ma Z, et al. Radiomics signature: a potential biomarker for the prediction of disease-free survival in early-stage (I or II) non-small cell lung cancer. Radiology 2016;281:947-57.

59. Gnep K, Fargeas A, Gutierrez-Carvajal RE, Commandeur F, Mathieu R, Ospina JD, et al. Haralick textural features on T2-weighted MRI are associated with biochemical recurrence following radiotherapy for peripheral zone prostate cancer. J Magn Reson Imaging 2017;45:103-17.

60. Huynh E, Coroller TP, Narayan V, Agrawal V, Hou Y, Romano J, et al. CT-based radiomic analysis of stereotactic body radiation therapy patients with lung cancer. Radiother Oncol 2016;120:258-66.

61. Huang YQ, Liang CH, He L, Tian J, Liang CS, Chen X, et al. Development and validation of a radiomics nomogram for preoperative prediction of lymph node metastasis in colorectal cancer. J Clin Oncol 2016;34:2157-64.

62. Liang C, Huang Y, He L, Chen X, Ma Z, Dong D, et al. The development and validation of a CT-based radiomics signature for the preoperative discrimination of stage I-II and stage III-IV colorectal cancer. Oncotarget 2016; 7:31401-12.

63. Coroller TP, Agrawal V, Narayan V, Hou Y, Grossmann P, Lee SW, et al. Radiomic phenotype features predict pathological response in non-small cell lung cancer. Radio- ther Oncol 2016;119:480-6.

64. Wu W, Parmar C, Grossmann P, Quackenbush J, Lambin $\mathrm{P}$, Bussink J, et al. Exploratory study to identify radiomics classifiers for lung cancer histology. Front Oncol 2016; 6:71.

65. van Velden FH, Kramer GM, Frings V, Nissen IA, Mulder ER, de Langen AJ, et al. Repeatability of radiomic features in non-small-cell lung cancer [(18)F]FDG-PET/CT studies: impact of reconstruction and delineation. Mol Imaging Biol 2016;18:788-95.

66. Mattonen SA, Palma DA, Johnson C, Louie AV, Landis M, Rodrigues $\mathrm{G}$, et al. Detection of local cancer recurrence after stereotactic ablative radiation therapy for lung cancer: physician performance versus radiomic assessment. Int J Radiat Oncol Biol Phys 2016;94:1121-8.

67. Ghosh P, Tamboli P, Vikram R, Rao A. Imaging-genomic pipeline for identifying gene mutations using three-dimensional intra-tumor heterogeneity features. J Med Imaging (Bellingham) 2015;2:041009.

68. Mattonen SA, Tetar S, Palma DA, Louie AV, Senan S, Ward AD. Imaging texture analysis for automated prediction of lung cancer recurrence after stereotactic radiotherapy. J Med Imaging (Bellingham) 2015;2:041010.

69. Lee J, Narang S, Martinez JJ, Rao G, Rao A. Associating spatial diversity features of radiologically defined tumor habitats with epidermal growth factor receptor driver status and 12-month survival in glioblastoma: methods and preliminary investigation. J Med Imaging (Bellingham) 2015;2:041006.

70. Parmar C, Grossmann P, Rietveld D, Rietbergen MM, Lambin P, Aerts HJ. Radiomic machine-learning classifiers for prognostic biomarkers of head and neck cancer. Front Oncol 2015;5:272.

71. Oliver JA, Budzevich M, Zhang GG, Dilling TJ, Latifi K, Moros EG. Variability of image features computed from conventional and respiratory-gated PET/CT images of lung cancer. Transl Oncol 2015;8:524-34.

72. Fave X, Mackin D, Yang J, Zhang J, Fried D, Balter P, et al. Can radiomics features be reproducibly measured from CBCT images for patients with non-small cell lung cancer? Med Phys 2015;42:6784-97.

73. Wang J, Kato F, Oyama-Manabe N, Li R, Cui Y, Tha KK, et al. Identifying triple-negative breast cancer using background parenchymal enhancement heterogeneity on dynamic contrast-enhanced MRI: a pilot radiomics study. PLoS One 2015;10:e0143308.

74. Echegaray S, Gevaert O, Shah R, Kamaya A, Louie J, Ko- 
thary $\mathrm{N}$, et al. Core samples for radiomics features that are insensitive to tumor segmentation: method and pilot study using CT images of hepatocellular carcinoma. J Med Imaging (Bellingham) 2015;2:041011.

75. Cameron A, Khalvati F, Haider MA, Wong A. MAPS: a quantitative radiomics approach for prostate cancer detection. IEEE Trans Biomed Eng 2016;63:1145-56.

76. Ypsilantis PP, Siddique M, Sohn HM, Davies A, Cook G, $\mathrm{Goh} V$, et al. Predicting response to neoadjuvant chemotherapy with PET imaging using convolutional neural networks. PLoS One 2015;10:e0137036.

77. Parmar C, Leijenaar RT, Grossmann P, Rios Velazquez E, Bussink J, Rietveld D, et al. Radiomic feature clusters and prognostic signatures specific for lung and head \& neck cancer. Sci Rep 2015;5:11044.

78. Khalvati F, Wong A, Haider MA. Automated prostate cancer detection via comprehensive multi-parametric magnetic resonance imaging texture feature models. BMC Med Imaging 2015;15:27.

79. Leijenaar RT, Nalbantov G, Carvalho S, van Elmpt WJ, Troost EG, Boellaard R, et al. The effect of SUV discretization in quantitative FDG-PET radiomics: the need for standardized methodology in tumor texture analysis. Sci Rep 2015;5:11075.

80. Vallieres M, Freeman CR, Skamene SR, El Naqa I. A radiomics model from joint FDG-PET and MRI texture features for the prediction of lung metastases in soft-tissue sarcomas of the extremities. Phys Med Biol 2015;60:547196.

81. Mackin D, Fave X, Zhang L, Fried D, Yang J, Taylor B, et al. Measuring computed tomography scanner variability of radiomics features. Invest Radiol 2015;50:757-65.

82. Coroller TP, Grossmann P, Hou Y, Rios Velazquez E, Leijenaar RT, Hermann G, et al. CT-based radiomic signature predicts distant metastasis in lung adenocarcinoma. Radiother Oncol 2015;114:345-50.

83. Cunliffe A, Armato SG 3rd, Castillo R, Pham N, Guerrero T, Al-Hallaq HA. Lung texture in serial thoracic computed tomography scans: correlation of radiomics-based features with radiation therapy dose and radiation pneumonitis development. Int J Radiat Oncol Biol Phys 2015; 91:1048-56.

84. Parmar C, Rios Velazquez E, Leijenaar R, Jermoumi M, Carvalho S, Mak RH, et al. Robust radiomics feature quantification using semiautomatic volumetric segmentation. PLoS One 2014;9:e102107.

85. Velazquez ER, Parmar C, Jermoumi M, Mak RH, van Baar- dwijk A, Fennessy FM, et al. Volumetric CT-based segmentation of NSCLC using 3D-slicer. Sci Rep 2013;3:3529.

86. Halpenny DF, Plodkowski A, Riely G, Zheng J, Litvak A, Moscowitz C, et al. Radiogenomic evaluation of lung cancer: are there imaging characteristics associated with lung adenocarcinomas harboring BRAF mutations? Clin Imaging 2017;42:147-51.

87. Demerath T, Simon-Gabriel CP, Kellner E, Schwarzwald $\mathrm{R}$, Lange T, Heiland DH, et al. Mesoscopic imaging of glioblastomas: are diffusion, perfusion and spectroscopic measures influenced by the radiogenetic phenotype? Neuroradiol J 2017;30:36-47.

88. Wiestler B, Kluge A, Lukas M, Gempt J, Ringel F, Schlegel $\mathrm{J}$, et al. Multiparametric MRI-based differentiation of WHO grade II/III glioma and WHO grade IV glioblastoma. Sci Rep 2016;6:35142.

89. Kickingereder P, Bonekamp D, Nowosielski M, Kratz A, Sill M, Burth S, et al. Radiogenomics of glioblastoma: machine learning-based classification of molecular characteristics by using multiparametric and multiregional MR imaging features. Radiology 2016;281:907-18.

90. Heiland DH, Demerath T, Kellner E, Kiselev VG, Pfeifer D, Schnell O, et al. Molecular differences between cerebral blood volume and vessel size in glioblastoma multiforme. Oncotarget. 2016 Aug 23 [Epub]. http://doi.org/10.18632/ oncotarget.11522.

91. Hu LS, Ning S, Eschbacher JM, Baxter LC, Gaw N, Ranjbar S, et al. Radiogenomics to characterize regional genetic heterogeneity in glioblastoma. Neuro Oncol 2017; 19:128-37.

92. Saha A, Grimm LJ, Harowicz M, Ghate SV, Kim C, Walsh R, et al. Interobserver variability in identification of breast tumors in MRI and its implications for prognostic biomarkers and radiogenomics. Med Phys 2016;43:4558.

93. Mehta S, Hughes NP, Li S, Jubb A, Adams R, Lord S, et al. Radiogenomics monitoring in breast cancer identifies metabolism and immune checkpoints as early actionable mechanisms of resistance to anti-angiogenic treatment. EBioMedicine 2016;10:109-16.

94. Stoyanova R, Pollack A, Takhar M, Lynne C, Parra N, Lam $\mathrm{LL}$, et al. Association of multiparametric MRI quantitative imaging features with prostate cancer gene expression in MRI-targeted prostate biopsies. Oncotarget 2016; 7:53362-76.

95. Zhao B, Tan Y, Tsai WY, Qi J, Xie C, Lu L, et al. Reproducibility of radiomics for deciphering tumor phenotype with imaging. Sci Rep 2016;6:23428. 
96. McCann SM, Jiang Y, Fan X, Wang J, Antic T, Prior F, et al. Quantitative multiparametric MRI features and PTEN expression of peripheral zone prostate cancer: a pilot study. AJR Am J Roentgenol 2016;206:559-65.

97. Guo W, Li H, Zhu Y, Lan L, Yang S, Drukker K, et al. Prediction of clinical phenotypes in invasive breast carcinomas from the integration of radiomics and genomics data. J Med Imaging (Bellingham) 2015;2:041007.

98. Zhu Y, Li H, Guo W, Drukker K, Lan L, Giger ML, et al. Deciphering genomic underpinnings of quantitative MRIbased radiomic phenotypes of invasive breast carcinoma. Sci Rep 2015;5:17787.

99. Kickingereder P, Sahm F, Radbruch A, Wick W, Heiland S, Deimling A, et al. IDH mutation status is associated with a distinct hypoxia/angiogenesis transcriptome signature which is non-invasively predictable with $\mathrm{rCBV}$ imaging in human glioma. Sci Rep 2015;5:16238.

100. Rao A, Rao G, Gutman DA, Flanders AE, Hwang SN, Rubin $\mathrm{DL}$, et al. A combinatorial radiographic phenotype may stratify patient survival and be associated with invasion and proliferation characteristics in glioblastoma. J Neurosurg 2016;124:1008-17.

101. Gutman DA, Dunn WD Jr, Grossmann P, Cooper LA, Holder CA, Ligon KL, et al. Somatic mutations associated with MRI-derived volumetric features in glioblastoma. Neuroradiology 2015;57:1227-37.

102. Renard-Penna R, Cancel-Tassin G, Comperat E, Varinot J, Leon $\mathrm{P}$, Roupret $\mathrm{M}$, et al. Multiparametric magnetic resonance imaging predicts postoperative pathology but misses aggressive prostate cancers as assessed by cell cycle progression score. J Urol 2015;194:1617-23.

103. Shinagare AB, Vikram R, Jaffe C, Akin O, Kirby J, Huang E, et al. Radiogenomics of clear cell renal cell carcinoma: preliminary findings of The Cancer Genome Atlas-Renal Cell Carcinoma (TCGA-RCC) Imaging Research Group. Abdom Imaging 2015;40:1684-92.

104. Wang Y, Zhang T, Li S, Fan X, Ma J, Wang L, et al. Anatomical localization of isocitrate dehydrogenase 1 mutation: a voxel-based radiographic study of 146 low-grade gliomas. Eur J Neurol 2015;22:348-54.

105. Halpenny DF, Riely GJ, Hayes S, Yu H, Zheng J, Moskowitz CS, et al. Are there imaging characteristics associated with lung adenocarcinomas harboring ALK rearrangements? Lung Cancer 2014;86:190-4.

106. Gevaert O, Mitchell LA, Achrol AS, Xu J, Echegaray S, Steinberg GK, et al. Glioblastoma multiforme: exploratory radiogenomic analysis by using quantitative image fea- tures. Radiology 2014;273:168-74.

107. Nair VS, Gevaert O, Davidzon G, Plevritis SK, West R. NFkappaB protein expression associates with (18)F-FDG PET tumor uptake in non-small cell lung cancer: a radiogenomics validation study to understand tumor metabolism. Lung Cancer 2014;83:189-96.

108. Jamshidi N, Diehn M, Bredel M, Kuo MD. Illuminating radiogenomic characteristics of glioblastoma multiforme through integration of MR imaging, messenger RNA expression, and DNA copy number variation. Radiology 2014;270:1-2.

109. Karlo CA, Di Paolo PL, Chaim J, Hakimi AA, Ostrovnaya I, Russo P, et al. Radiogenomics of clear cell renal cell carcinoma: associations between CT imaging features and mutations. Radiology 2014;270:464-71.

110. De Ruysscher D, Sharifi H, Defraene G, Kerns SL, Christiaens M, De Ruyck K, et al. Quantification of radiationinduced lung damage with CT scans: the possible benefit for radiogenomics. Acta Oncol 2013;52:1405-10.

111. Zinn PO, Mahajan B, Sathyan P, Singh SK, Majumder S, Jolesz FA, et al. Radiogenomic mapping of edema/cellular invasion MRI-phenotypes in glioblastoma multiforme. PLoS One 2011;6:e25451.

112. Lee HY, Lee KS. Ground-glass opacity nodules: histopathology, imaging evaluation, and clinical implications. J Thorac Imaging 2011;26:106-18.

113. Min JH, Lee HY, Lee KS, Han J, Park K, Ahn MJ, et al. Stepwise evolution from a focal pure pulmonary ground-glass opacity nodule into an invasive lung adenocarcinoma: an observation for more than 10 years. Lung Cancer 2010; 69:123-6.

114. Eguchi T, Yoshizawa A, Kawakami S, Kumeda H, Umesaki T, Agatsuma $\mathrm{H}$, et al. Tumor size and computed tomography attenuation of pulmonary pure ground-glass nodules are useful for predicting pathological invasiveness. PLoS One 2014;9:e97867.

115. Lee HY, Choi YL, Lee KS, Han J, Zo JI, Shim YM, et al. Pure ground-glass opacity neoplastic lung nodules: histopathology, imaging, and management. AJR Am J Roentgenol 2014;202:W224-33.

116. Ikeda K, Awai K, Mori T, Kawanaka K, Yamashita Y, Nomori $\mathrm{H}$. Differential diagnosis of ground-glass opacity nodules: CT number analysis by three-dimensional computerized quantification. Chest 2007;132:984-90.

117. Ko JP, Suh J, Ibidapo O, Escalon JG, Li J, Pass H, et al. Lung adenocarcinoma: correlation of quantitative CT findings with pathologic findings. Radiology 2016;280: 


\section{PRECISION AND FUTURE MIEDICINE \\ Radiomics and imaging genomics}

931-9.

118. Son JY, Lee HY, Lee KS, Kim JH, Han J, Jeong JY, et al. Quantitative CT analysis of pulmonary ground-glass opacity nodules for the distinction of invasive adenocarcinoma from pre-invasive or minimally invasive adenocarcinoma. PLoS One 2014;9:e104066.

119. Bak SH, Lee HY, Kim JH, Um SW, Kwon OJ, Han J, et al. Quantitative CT scanning analysis of pure ground-glass opacity nodules predicts further CT scanning change. Chest 2016;149:180-91.

120. James D, Clymer BD, Schmalbrock P. Texture detection of simulated microcalcification susceptibility effects in magnetic resonance imaging of breasts. J Magn Reson Imaging 2001;13:876-81.

121. Chen W, Giger ML, Li H, Bick U, Newstead GM. Volumetric texture analysis of breast lesions on contrast-enhanced magnetic resonance images. Magn Reson Med 2007; 58:562-71.

122. Gibbs P, Turnbull LW. Textural analysis of contrast-enhanced MR images of the breast. Magn Reson Med 2003; 50:92-8.

123. Woods BJ, Clymer BD, Kurc T, Heverhagen JT, Stevens R, Orsdemir A, et al. Malignant-lesion segmentation using 4D co-occurrence texture analysis applied to dynamic contrast-enhanced magnetic resonance breast image data. J Magn Reson Imaging 2007;25:495-501.

124. Holli K, Laaperi AL, Harrison L, Luukkaala T, Toivonen T, Ryymin $P$, et al. Characterization of breast cancer types by texture analysis of magnetic resonance images. Acad Radiol 2010;17:135-41.

125. Waugh SA, Purdie CA, Jordan LB, Vinnicombe S, Lerski $\mathrm{RA}$, Martin P, et al. Magnetic resonance imaging texture analysis classification of primary breast cancer. Eur Radiol 2016;26:322-30.

126. Parikh J, Selmi M, Charles-Edwards G, Glendenning J, Ganeshan B, Verma H, et al. Changes in primary breast cancer heterogeneity may augment midtreatment MR imaging assessment of response to neoadjuvant chemotherapy. Radiology 2014;272:100-12.

127. Pickles MD, Lowry M, Gibbs P. Pretreatment prognostic value of dynamic contrast-enhanced magnetic resonance imaging vascular, texture, shape, and size parameters compared with traditional survival indicators obtained from locally advanced breast cancer patients. Invest Radiol 2016;51:177-85.

128. Kim JH, Ko ES, Lim Y, Lee KS, Han BK, Ko EY, et al. Breast cancer heterogeneity: MR imaging texture analysis and survival outcomes. Radiology 2017;282:665-75.

129. Hesketh RL, Zhu AX, Oklu R. Hepatocellular carcinoma: can circulating tumor cells and radiogenomics deliver personalized care? Am J Clin Oncol 2015;38:431-6.

130. Castellano G, Bonilha L, Li LM, Cendes F. Texture analysis of medical images. Clin Radiol 2004;59:1061-9.

131. Wolfort RM, Papillion PW, Turnage RH, Lillien DL, Ramaswamy MR, Zibari GB. Role of FDG-PET in the evaluation and staging of hepatocellular carcinoma with comparison of tumor size, AFP level, and histologic grade. Int Surg 2010;95:67-75.

132. Day SE, Kettunen MI, Gallagher FA, Hu DE, Lerche M, Wolber J, et al. Detecting tumor response to treatment using hyperpolarized $13 \mathrm{C}$ magnetic resonance imaging and spectroscopy. Nat Med 2007;13:1382-7.

133. Lee J, Kim SH, Kang TW, Song KD, Choi D, Jang KT. Massforming intrahepatic cholangiocarcinoma: diffusionweighted imaging as a preoperative prognostic marker. Radiology 2016;281:119-28.

134. Kim KA, Kim MJ, Jeon HM, Kim KS, Choi JS, Ahn SH, et al. Prediction of microvascular invasion of hepatocellular carcinoma: usefulness of peritumoral hypointensity seen on gadoxetate disodium-enhanced hepatobiliary phase images. J Magn Reson Imaging 2012;35:629-34.

135. Korn RL, Crowley JJ. Overview: progression-free survival as an endpoint in clinical trials with solid tumors. Clin Cancer Res 2013;19:2607-12.

136. Zhan P, Ji YN, Yu LK. TP53 mutation is associated with a poor outcome for patients with hepatocellular carcinoma: evidence from a meta-analysis. Hepatobiliary Surg Nutr 2013;2:260-5.

137. Mao TL, Chu JS, Jeng YM, Lai PL, Hsu HC. Expression of mutant nuclear beta-catenin correlates with non-invasive hepatocellular carcinoma, absence of portal vein spread, and good prognosis. J Pathol 2001;193:95-101.

138. Lee JS, Heo J, Libbrecht L, Chu IS, Kaposi-Novak P, Calvisi DF, et al. A novel prognostic subtype of human hepatocellular carcinoma derived from hepatic progenitor cells. Nat Med 2006;12:410-6.

139. Thelen A, Scholz A, Weichert W, Wiedenmann B, Neuhaus $P$, Gessner R, et al. Tumor-associated angiogenesis and lymphangiogenesis correlate with progression of intrahepatic cholangiocarcinoma. Am J Gastroenterol 2010;105:1123-32.

140. Yoshikawa D, Ojima H, Iwasaki M, Hiraoka N, Kosuge T, Kasai S, et al. Clinicopathological and prognostic significance of EGFR, VEGF, and HER2 expression in cholan- 
giocarcinoma. Br J Cancer 2008;98:418-25.

141. Voss JS, Holtegaard LM, Kerr SE, Fritcher EG, Roberts LR, Gores GJ, et al. Molecular profiling of cholangiocarcinoma shows potential for targeted therapy treatment decisions. Hum Pathol 2013;44:1216-22.

142. Ng F, Kozarski R, Ganeshan B, Goh V. Assessment of tumor heterogeneity by $\mathrm{CT}$ texture analysis: can the largest cross-sectional area be used as an alternative to whole tumor analysis? Eur J Radiol 2013;82:342-8.

143. Ng F, Ganeshan B, Kozarski R, Miles KA, Goh V. Assessment of primary colorectal cancer heterogeneity by using whole-tumor texture analysis: contrast-enhanced CT texture as a biomarker of 5-year survival. Radiology 2013; 266:177-84.

144. Ganeshan B, Miles KA, Young RC, Chatwin CR. Texture analysis in non-contrast enhanced $\mathrm{CT}$ : impact of malignancy on texture in apparently disease-free areas of the liver. Eur J Radiol 2009;70:101-10.

145. Rao SX, Lambregts DM, Schnerr RS, Beckers RC, Maas M, Albarello F, et al. CT texture analysis in colorectal liver metastases: a better way than size and volume measurements to assess response to chemotherapy? United European Gastroenterol J 2016;4:257-63.

146. Ahn SJ, Kim JH, Park SJ, Han JK. Prediction of the therapeutic response after FOLFOX and FOLFIRI treatment for patients with liver metastasis from colorectal cancer using computerized CT texture analysis. Eur J Radiol 2016;85:1867-74.

147. Galavis PE, Hollensen C, Jallow N, Paliwal B, Jeraj R. Variability of textural features in FDG PET images due to different acquisition modes and reconstruction parameters. Acta Oncol 2010;49:1012-6.

148. Kumar V, Gu Y, Basu S, Berglund A, Eschrich SA, Schabath $M B$, et al. Radiomics: the process and the challenges. Magn Reson Imaging 2012;30:1234-48.

149. Yan J, Chu-Shern JL, Loi HY, Khor LK, Sinha AK, Quek ST, et al. Impact of image reconstruction settings on texture features in 18F-FDG PET. J Nucl Med 2015;56:1667-73.

150. Rios Velazquez E, Aerts HJ, Gu Y, Goldgof DB, De Ruysscher D, Dekker A, et al. A semiautomatic CT-based ensemble segmentation of lung tumors: comparison with oncologists' delineations and with the surgical specimen. Radiother Oncol 2012;105:167-73.

151. van Dam IE, van Sornsen de Koste JR, Hanna GG, Muirhead R, Slotman BJ, Senan S. Improving target delineation on 4-dimensional CT scans in stage I NSCLC using a deformable registration tool. Radiother Oncol 2010;96:
67-72.

152. Heye T, Merkle EM, Reiner CS, Davenport MS, Horvath $\mathrm{JJ}$, Feuerlein S, et al. Reproducibility of dynamic contrast-enhanced MR imaging. Part II. Comparison of intraand interobserver variability with manual region of interest placement versus semiautomatic lesion segmentation and histogram analysis. Radiology 2013;266:81221.

153. Park J, Kobayashi Y, Urayama KY, Yamaura H, Yatabe $\mathrm{Y}$, Hida T. Imaging characteristics of driver mutations in EGFR, KRAS, and ALK among treatment-naive patients with advanced lung adenocarcinoma. PLoS One 2016; 11:e0161081.

154. Kwak EL, Bang YJ, Camidge DR, Shaw AT, Solomon B, Maki RG, et al. Anaplastic lymphoma kinase inhibition in non-small-cell lung cancer. N Engl J Med 2010;363: 1693-703.

155. Pirker R, Filipits M. Personalized treatment of advanced non-small-cell lung cancer in routine clinical practice. Cancer Metastasis Rev 2016;35:141-50.

156. Nair VS, Gevaert O, Davidzon G, Napel S, Graves EE, Hoang CD, et al. Prognostic PET 18F-FDG uptake imaging features are associated with major oncogenomic alterations in patients with resected non-small cell lung cancer. Cancer Res 2012;72:3725-34.

157. Dewhirst MW, Chi JT. Understanding the tumor microenvironment and radioresistance by combining functional imaging with global gene expression. Semin Radiat Oncol 2013;23:296-305.

158. Jeong CJ, Lee HY, Han J, Jeong JY, Lee KS, Choi YL, et al. Role of imaging biomarkers in predicting anaplastic lymphoma kinase-positive lung adenocarcinoma. Clin Nucl Med 2015;40:e34-9.

159. Lam SW, Jimenez CR, Boven E. Breast cancer classification by proteomic technologies: current state of knowledge. Cancer Treat Rev 2014;40:129-38.

160. Wirapati P, Sotiriou C, Kunkel S, Farmer P, Pradervand S, Haibe-Kains B, et al. Meta-analysis of gene expression profiles in breast cancer: toward a unified understanding of breast cancer subtyping and prognosis signatures. Breast Cancer Res 2008;10:R65.

161. Carey LA, Dees EC, Sawyer L, Gatti L, Moore DT, Collichio F, et al. The triple negative paradox: primary tumor chemosensitivity of breast cancer subtypes. Clin Cancer Res 2007;13:2329-34.

162. Grimm LJ, Johnson KS, Marcom PK, Baker JA, Soo MS. Can breast cancer molecular subtype help to select pa- 


\section{PRECISION AND FUTURE MIEDICINE}

Radiomics and imaging genomics

tients for preoperative MR imaging? Radiology 2015;274: 352-8.

163. Smid M, Wang Y, Zhang Y, Sieuwerts AM, Yu J, Klijn JG, et al. Subtypes of breast cancer show preferential site of relapse. Cancer Res 2008;68:3108-14.

164. Kyndi M, Sorensen FB, Knudsen H, Overgaard M, Nielsen HM, Overgaard J, et al. Estrogen receptor, progesterone receptor, HER-2, and response to postmastectomy radiotherapy in high-risk breast cancer: the Danish Breast Cancer Cooperative Group. J Clin Oncol 2008;26:141926.

165. Goldhirsch A, Winer EP, Coates AS, Gelber RD, PiccartGebhart M, Thurlimann B, et al. Personalizing the treatment of women with early breast cancer: highlights of the St Gallen International Expert Consensus on the Primary Therapy of Early Breast Cancer 2013. Ann Oncol 2013;24:2206-23.

166. Carey LA, Perou CM, Livasy CA, Dressler LG, Cowan D, Conway K, et al. Race, breast cancer subtypes, and survival in the Carolina Breast Cancer Study. JAMA 2006; 295:2492-502.

167. Huber KE, Carey LA, Wazer DE. Breast cancer molecular subtypes in patients with locally advanced disease: impact on prognosis, patterns of recurrence, and response to therapy. Semin Radiat Oncol 2009;19:204-10.

168. Guiu S, Michiels S, Andre F, Cortes J, Denkert C, Di Leo A, et al. Molecular subclasses of breast cancer: how do we define them? The IMPAKT 2012 Working Group Statement. Ann Oncol 2012;23:2997-3006.

169. Griffith OL, Gray JW. 'Omic approaches to preventing or managing metastatic breast cancer. Breast Cancer Res 2011;13:230.

170. Kittaneh M, Montero AJ, Gluck S. Molecular profiling for breast cancer: a comprehensive review. Biomark Cancer 2013;5:61-70.

171. Gradishar WJ, Anderson BO, Blair SL, Burstein HJ, Cyr A, Elias AD, et al. Breast cancer version 3.2014. J Natl Compr Canc Netw 2014;12:542-90.

172. Harris L, Fritsche H, Mennel R, Norton L, Ravdin P, Taube S, et al. American Society of Clinical Oncology 2007 update of recommendations for the use of tumor markers in breast cancer. J Clin Oncol 2007;25:5287-312.

173. Ashraf AB, Daye D, Gavenonis S, Mies C, Feldman M, Rosen $\mathrm{M}$, et al. Identification of intrinsic imaging phenotypes for breast cancer tumors: preliminary associations with gene expression profiles. Radiology 2014;272:37484.
174. Dialani V, Gaur S, Mehta TS, Venkataraman S, Fein-Zachary V, Phillips J, et al. Prediction of low versus high recurrence scores in estrogen receptor-positive, lymph node-negative invasive breast cancer on the basis of radiologic-pathologic features: comparison with Oncotype DX test recurrence scores. Radiology 2016;280:370-8.

175. Sutton EJ, Oh JH, Dashevsky BZ, Veeraraghavan H, Apte AP, Thakur SB, et al. Breast cancer subtype intertumor heterogeneity: MRI-based features predict results of a genomic assay. J Magn Reson Imaging 2015;42:1398406.

176. Segal E, Sirlin CB, Ooi C, Adler AS, Gollub J, Chen X, et al. Decoding global gene expression programs in liver cancer by noninvasive imaging. Nat Biotechnol 2007;25:67580.

177. Banerjee S, Wang DS, Kim HJ, Sirlin CB, Chan MG, Korn $\mathrm{RL}$, et al. A computed tomography radiogenomic biomarker predicts microvascular invasion and clinical outcomes in hepatocellular carcinoma. Hepatology 2015; 62:792-800.

178. Kitao A, Matsui O, Yoneda N, Kozaka K, Kobayashi S, Sanada J, et al. Hepatocellular carcinoma with beta-catenin mutation: imaging and pathologic characteristics. Radiology 2015;275:708-17.

179. Kuo MD, Gollub J, Sirlin CB, Ooi C, Chen X. Radiogenomic analysis to identify imaging phenotypes associated with drug response gene expression programs in hepatocellular carcinoma. J Vasc Interv Radiol 2007;18:82131.

180. Sadot E, Simpson AL, Do RK, Gonen M, Shia J, Allen PJ, et al. Cholangiocarcinoma: correlation between molecular profiling and imaging phenotypes. PLoS One 2015; 10:e0132953.

181. Borbath I, Ceratti A, Verslype C, Demols A, Delaunoit T, Laurent $S$, et al. Combination of gemcitabine and cetuximab in patients with advanced cholangiocarcinoma: a phase II study of the Belgian Group of Digestive Oncology. Ann Oncol 2013;24:2824-9.

182. Lubner SJ, Mahoney MR, Kolesar JL, Loconte NK, Kim GP, Pitot HC, et al. Report of a multicenter phase II trial testing a combination of biweekly bevacizumab and daily erlotinib in patients with unresectable biliary cancer: a phase II Consortium study. J Clin Oncol 2010;28: 3491-7.

183. Keeratichamroen S, Leelawat K, Thongtawee T, Narong $\mathrm{S}$, Aegem $\mathrm{U}$, Tujinda S, et al. Expression of CD24 in cholangiocarcinoma cells is associated with disease progres- 
sion and reduced patient survival. Int J Oncol 2011;39: 873-81.

184. Balagurunathan Y, Gu Y, Wang H, Kumar V, Grove O, Hawkins $\mathrm{S}$, et al. Reproducibility and prognosis of quantitative features extracted from CT images. Transl Oncol 2014;7:72-87.

185. Balagurunathan Y, Kumar V, Gu Y, Kim J, Wang H, Liu Y, et al. Test-retest reproducibility analysis of lung CT image features. J Digit Imaging 2014;27:805-23.

186. Tixier F, Hatt M, Le Rest CC, Le Pogam A, Corcos L, Visvi- kis D. Reproducibility of tumor uptake heterogeneity characterization through textural feature analysis in $18 \mathrm{~F}$ FDG PET. J Nucl Med 2012;53:693-700.

187. Condon BR, Patterson J, Wyper D, Jenkins A, Hadley DM. Image non-uniformity in magnetic resonance imaging: its magnitude and methods for its correction. Br J Radiol 1987;60:83-7.

188. Vovk U, Pernus F, Likar B. A review of methods for correction of intensity inhomogeneity in MRI. IEEE Trans Med Imaging 2007;26:405-21. 